2013

\title{
VERIFYING SUCCESS OF ARTIFICIAL REEFS IN THE HURON-ERIE CORRIDOR FOR LAKE STURGEON
}

Emily K. Bouckaert

Michigan Technological University

Follow this and additional works at: https://digitalcommons.mtu.edu/etds

Part of the Biology Commons

Copyright 2013 Emily K. Bouckaert

\section{Recommended Citation}

Bouckaert, Emily K., "VERIFYING SUCCESS OF ARTIFICIAL REEFS IN THE HURON-ERIE CORRIDOR FOR LAKE STURGEON", Master's Thesis, Michigan Technological University, 2013.

https://doi.org/10.37099/mtu.dc.etds/452

Follow this and additional works at: https://digitalcommons.mtu.edu/etds

Part of the Biology Commons 
VERIFYING SUCCESS OF ARTIFICIAL REEFS IN THE HURON-ERIE CORRIDOR FOR LAKE STURGEON

\author{
By \\ Emily K. Bouckaert
}

\begin{abstract}
A THESIS
Submitted in partial fulfillment of the requirements for the degree of MASTER OF SCIENCE

In Biological Sciences
\end{abstract}

MICHIGAN TECHNOLOGICAL UNIVERSITY

2013

(C) 2013 Emily Bouckaert 
This thesis has been approved in partial fulfillment of the requirements for the Degree of MASTER OF SCIENCE in Biological Sciences.

\section{Department of Biological Sciences}

Thesis Advisor: Dr. Nancy A. Auer

Committee Member: Dr. Edward F. Roseman

Committee Member: $\quad$ Dr. Thomas D. Drummer

Department Chair: Dr. Nancy A. Auer 


\section{TABLE OF CONTENTS}

Preface

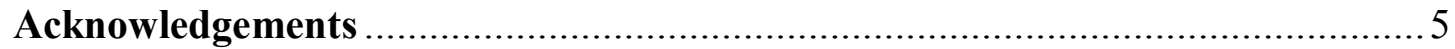

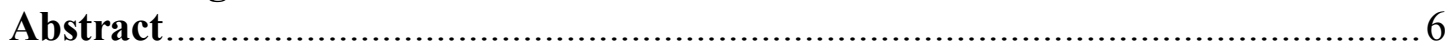

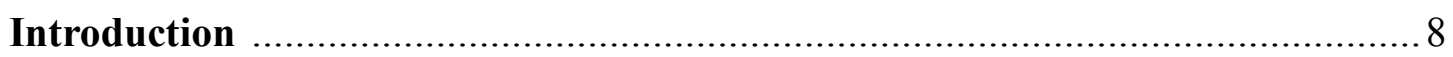

Chapter 1: Lake Sturgeon Egg \& Larval Field Studies

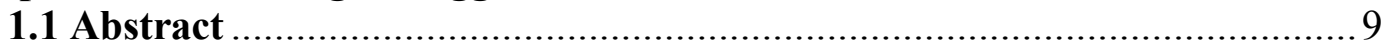

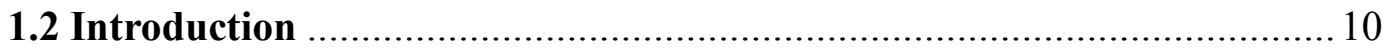

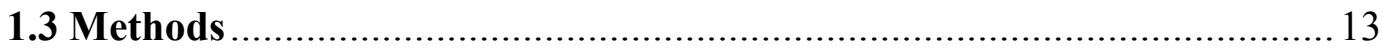

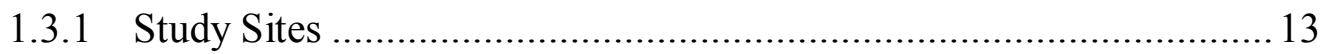

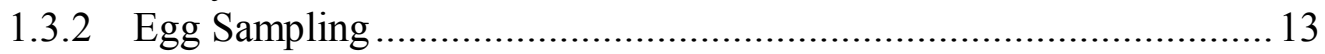

1.3.3 D-Frame Drift Net Larval Sampling ............................................... 14

1.3.4 Depth-Stratified Larval Sampling ................................................... 16

1.3.5 Sample Processing and Larval Fish Identification.............................. 17

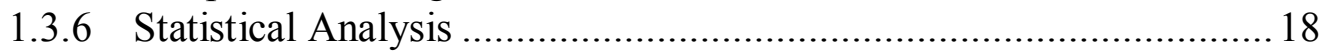

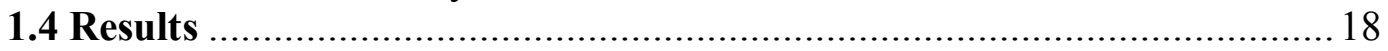

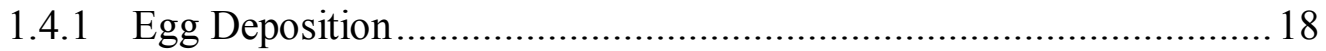

1.4.2 Larval D-Frame \& Depth Stratified Sampling .................................... 19

1.4.2.1 Fighting Island Reef........................................................19

1.4.2.2 Lower St. Clair River ....................................................... 20

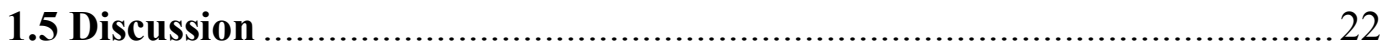

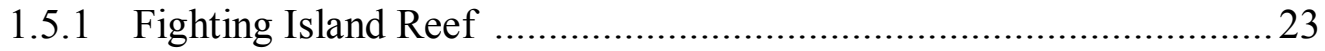

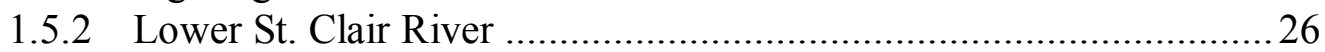

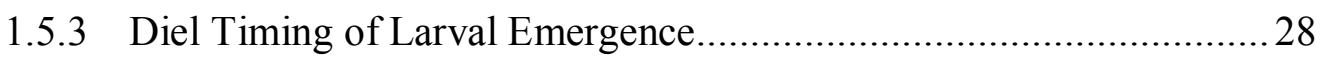

1.5.4 Depth-Stratified Larval Sampling ...................................................28

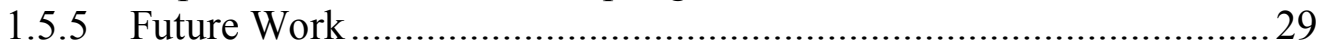

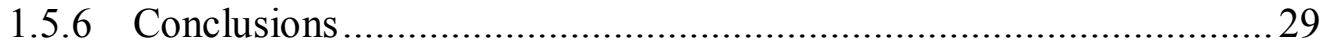

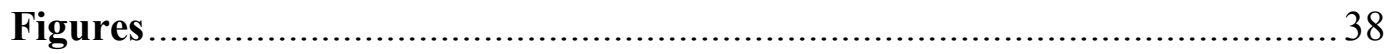

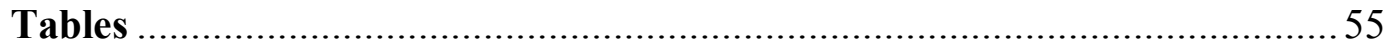

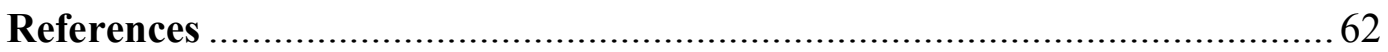

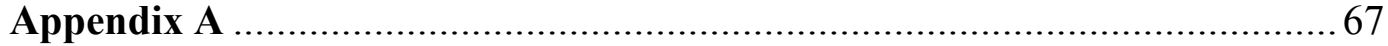

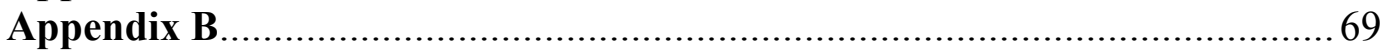

2. Artificial Reef Substrate Laboratory Experiment

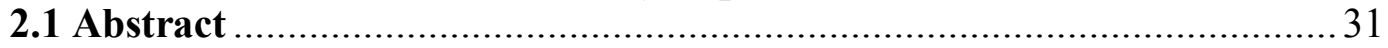

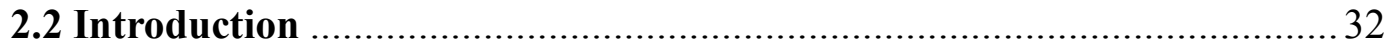

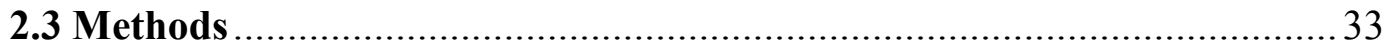

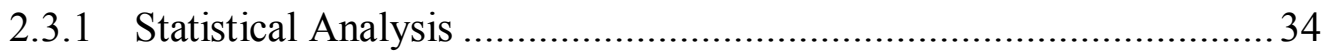

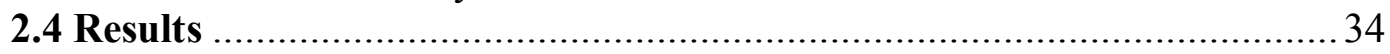

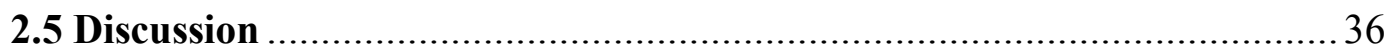

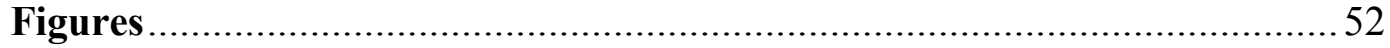

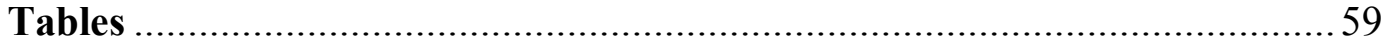

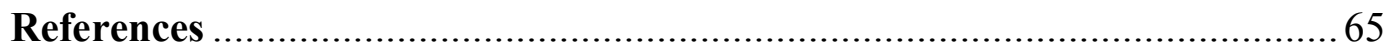




\section{PREFACE}

Chapter one of this thesis was a collaborate effort between four co-authors. I collected data in the field, analyzed the data, and wrote this chapter. Dr. Nancy Auer of Michigan Technological University, Houghton, MI provided technical assistance with data analysis and writing for this chapter. Dr. Edward Roseman of the USGS Great Lakes Science Center, Ann Arbor, MI procured funding for this project, assisted with data collection, and provided technical writing assistance for this chapter. James Boase of the USFWS, Waterford, MI assisted in procuring funding for this project and assisted with data collection. 


\section{ACKNOWLEDGEMENTS}

This work was supported by the Great Lakes Restoration Initiative Project \#70 - Fish Habitat Enhancement Strategies for the Huron-Erie Corridor and the USGS Science Support Program Project 10-R3-04.

First, I would like to acknowledge my committee members for their support throughout this project. I would like to thank my advisor, Dr. Nancy Auer whose expertise, patience, and advice have been invaluable in the process of producing this thesis. Her enthusiasm for research and teaching is inspiring. I would also like to thank Dr. Edward Roseman for giving me this opportunity and for his tireless effort to help me and my coworkers obtain the resources that we need in order to conduct good science. Finally, I would like to thank Dr.Thomas Drummer for his assistance with experimental design, and statistical analysis.

Additionally, this work would not have been possible without the field, laboratory, technical, and administrative support of many individuals including: Nick Arend, Patricia Asselin, Rhonda Aton, Dr. Susan Bagley, Dave Bennion, Emily Betterly, James Boase, Dustin Bowser, Chantelle Caldwell, Justin Chiotti, Jaquie Craig, Dr. Ruppali Datta, Robin DeBruyne, Jonathan Ebel, Tyler Genereaux, Ellen George, Thaddeus Gibson, Ashley Horne, Dr. Casey Huckins, Margaret Hutton, Stacey Ireland, Greg Kennedy, Theresa King, Jaime LeDuc, Kelsey Lincoln, Bruce Manny, Matthew McLean, Tony Matthys, Michael Nagel, Dr. Trevor Pitcher, Stacy Provo, Karen Soper, Aparupa Sengupta, Jenny Sutherland, Mike Thomas, Patricia Thompson, and Charlie Wootke.

I would also to acknowledge DTE energy for supplying the coal clinkers used in this study, the Ottawa Lake Quarry for supplying the limestone and BASF Corporation for the use of Fighting Island facilities for storage, dockage, and lodging.

Finally, to my wonderful, loving, and supportive family, thank you! 


\begin{abstract}
Lake sturgeon (Acipenser fulvescens) were historically abundant in the HuronErie Corridor (HEC), a $160 \mathrm{~km}$ river/channel network composed of the St. Clair River, Lake St. Clair, and the Detroit River that connects Lake Huron to Lake Erie. In the HEC, most natural lake sturgeon spawning substrates have been eliminated or degraded as a result of channelization and dredging. To address significant habitat loss in HEC, multiagency restoration efforts are underway to restore spawning substrate by constructing artificial spawning reefs. The main objective of this study was to conduct postconstruction monitoring of lake sturgeon egg deposition and larval emergence near two of these artificial reef projects; Fighting Island Reef in the Detroit River, and Middle Channel Spawning Reef in the lower St. Clair River. We also investigated seasonal and nightly timing of larval emergence, growth, and vertical distribution in the water column at these sites, and an additional site in the St. Clair River where lake sturgeon are known to spawn on a bed of $\sim 100$ year old coal clinkers. From $2010-12$, we collected viable eggs and larvae at all three sites indicating that these artificial reefs are creating conditions suitable for egg deposition, fertilization, incubation, and larval emergence. The construction methods and materials, and physical site conditions present in HEC artificial reef projects can be used to inform future spawning habitat restoration or enhancement efforts. The results from this study have also identified the likelihood of additional uncharacterized natural spawning sites in the St. Clair River.

In addition to the field study, we conducted a laboratory experiment involving actual substrate materials that have been used in artificial reef construction in this system. Although coal clinkers are chemically inert, some trace elements can be reincorporated
\end{abstract}


with the clinker material during the combustion process. Since lake sturgeon eggs and larvae are developing in close proximity to this material, it is important to measure the concentration of potentially toxic trace elements. This study focused on arsenic, which occurs naturally in coal and can be toxic to fishes. Total arsenic concentration was measured in samples taken from four substrate treatments submerged in distilled water; limestone cobble, rinsed limestone cobble, coal clinker, and rinsed coal clinker. Samples were taken at three time intervals: 24 hours, 11 days, and 21 days. ICP-MS analysis showed that concentrations of total arsenic were below the EPA drinking water standard (10 ppb) for all samples. However, at the 24 hour sampling interval, a two way repeated measures ANOVA with a Holm-Sidak post hoc analysis $(\alpha=0.05)$ showed that the mean arsenic concentration was significantly higher in the coal clinker substrate treatment then in the rinsed coal clinker treatment $(\mathrm{p}=0.006)$, the limestone cobble treatment $(\mathrm{p}<0.001)$, rinsed limestone cobble treatment $(\mathrm{p}<0.001)$ and the control $(\mathrm{p}<0.001)$ Additionally, mean arsenic concentration was significantly higher in the rinsed coal clinker treatment than the limestone cobble treatment $(\mathrm{p}=0.001)$, the rinsed limestone cobble treatment $(\mathrm{p}=0.009)$ and the control $(\mathrm{p}=0.002)$. While the effects of specifically exposing developing lake sturgeon to arsenic remain unstudied, the concentrations of total arsenic measured in this study are orders of magnitude lower than the EPA standards for fresh water aquatic life. 


\section{INTRODUCTION}

The first chapter of this thesis involved investigating the early life stages of lake sturgeon near artificial reefs in the Huron-Erie Corridor (HEC). The main objective of this study was to monitor these artificial reefs for egg deposition and larval emergence and also investigate seasonal and nightly timing of larval emergence, growth, and vertical distribution in the water column.

In the HEC, lake sturgeon spawn on coal clinkers, a waste product of coal combustion, in two locations (Manny and Kennedy 2002, Nichols et al. 2003, Caswell et al. 2004). Additionally, in 2004, coal clinkers were used as a reef substrate material in the construction of the Belle Isle Spawning Reef (Read and Manny 2006). Since lake sturgeon eggs and larvae are developing in close proximity to this material, it is important to investigate the potential toxicity of coal clinkers. The second chapter of this thesis involved measuring the concentration of total arsenic in samples collected from actual reef construction substrate materials (limestone \& coal clinkers) that had been submerged in water.

The spawning reef construction materials, methods, and site conditions discussed in these two chapters can help inform future spawning site restoration, enhancement, or creation projects. 


\subsection{ABSTRACT ${ }^{1}$}

Lake sturgeon (Acipenser fulvescens) were historically abundant in the HuronErie Corridor (HEC), a $160 \mathrm{~km}$ river/channel network composed of the St. Clair River, Lake St. Clair, and the Detroit River that connects Lake Huron to Lake Erie. However, at the turn of the $19^{\text {th }}$ century, lake sturgeon populations were dramatically reduced due to many factors including overexploitation, barriers to migration, and habitat loss. In the HEC, most natural lake sturgeon spawning substrates have been eliminated or degraded as a result of channelization and dredging. To address significant habitat loss in HEC, multi-agency restoration efforts are underway to restore spawning substrate by constructing artificial spawning reefs. The main objective of this study was to conduct post-construction monitoring of lake sturgeon egg deposition and larval emergence near two of these artificial reef projects; Fighting Island Reef in the Detroit River, and Middle Channel Spawning Reef in the lower St. Clair River. We also investigated seasonal and nightly timing of larval emergence, growth, and vertical distribution in the water column at these sites, and an additional site in the St. Clair River where lake sturgeon are known to spawn on a bed of $\sim 100$ year old coal clinkers. From 2010-12, we collected viable eggs and larvae at these sites indicating that these artificial reefs are creating conditions suitable for egg deposition, fertilization, incubation, and larval emergence. The construction methods and materials, and physical site conditions present in HEC artificial reef projects can be used to inform future spawning habitat restoration or enhancement efforts. The results from this study have also identified the likelihood of additional uncharacterized natural spawning sites in the St. Clair River.

\footnotetext{
${ }^{1}$ The material contained in this chapter is planned for submission to the Journal of Applied Ichthyology
} 


\subsection{INTRODUCTION}

Lake sturgeon (Acipenser fulvescens) were historically abundant in the HuronErie Corridor (HEC), a $160 \mathrm{~km}$ river/channel network composed of the St. Clair River (SCR), Lake St. Clair, and the Detroit River (DR) that connects Lake Huron to Lake Erie (Post 1890, Harkness and Dymond 1961, Hay-Chmielewski and Whelan 1997). This highly developed binational waterway forms a border between the eastern Lower Peninsula of Michigan, and western Ontario. In the $19^{\text {th }}$ and $20^{\text {th }}$ centuries, lake sturgeon populations were dramatically reduced in the Great Lakes basin (Harkness and Dymond 1961, Smith 1968, Wells and McLain 1973). Prior to 1860, commercial fisherman commonly removed and discarded lake sturgeon, considering them to be nuisance bycatch (Harkness and Dymond 1961, Baker 1980). Lake sturgeon populations were further reduced when their economic potential was realized in the late 1800s. Until fishing restrictions were enacted in the early 1900s, sturgeon were heavily harvested for many products including their flesh, eggs, skin, and swim bladders (Harkness and Dymond 1961, Smith 1968, Wells and McLain 1973). Additionally, lake sturgeon populations have been negatively affected by barriers to migration paths and the loss of spawning/nursery habitat (Auer 1996, Rochard et al.1990)

Similar to other regions in the Great Lakes basin, lake sturgeon population declines were evident in HEC by the late 1800s ( Harkness and Dymond 1961, HayChmielewski and Whelan 1997). This trend is highlighted in data compiled by Baldwin et al. (2009) which shows a decrease in commercial lake sturgeon production in Lake St. Clair from 494,869 kg in 1879 , to $126,099 \mathrm{~kg}$ in 1885 . As of 2012, the Michigan Department of Natural Resources permitted a limited harvest (one lake 
sturgeon/angler/year) in SCR and Lake St. Clair from 16 July to 30 September. No harvest is allowed in the DR, or in Canadian waters of the HEC.

Goodyear et al. (1982 a, b) provided historical evidence (mostly anecdotal) of lake sturgeon spawning at 15 sites within the HEC. Prior to 2009, only three spawning sites in this area were known to be active (Manny and Kennedy 2002, Nichols et al. 2003, Caswell et al. 2004). In the SCR, the largest site is in the headwaters region near the international Blue Water Bridge (Manny and Kennedy 2002, Nichols et al. 2003) (Table 1). The second known site, North Channel Reef (NCR) is an "accidental" artificial reef in the North Channel of the lower SCR (Manny and Kennedy 2002, Nichols et al. 2003) (Table 1). This reef was created by the deposition of coal clinker (referred to as "coal cinder" by other references) from coal powered steamships at the turn of the $19^{\text {th }}$ century (Baker 1980). The third known site is near Zug Island in the DR, where lake sturgeon spawn on glacial gravel and coal clinkers (Caswell et al. 2004, Manny and Kennedy 2002) (Table 1).

In the HEC, most natural limestone beds and cobble, important sturgeon spawning substrates, have been eliminated or degraded as a result of channelization and dredging (Larson 1981, Manny 2006, Roseman et al. 2011a). To address significant habitat loss in the HEC, multi-agency restoration efforts are underway to restore spawning substrate by constructing artificial reefs (Table 1, Appendix A). The objective of creating these artificial reefs is to enhance or establish additional spawning habitat for native fishes including lake sturgeon (Manny 2006, Roseman et al. 2011a). The HEC is recognized as an Area of Concern (AOC) by the International Joint Commission. In order to delist the $\mathrm{HEC}$ as an $\mathrm{AOC}, 14$ beneficial use impairments (BUI) must be 
addressed, one of which is the loss of fish and wildlife habitat. The goal of replacing or enhancing $10 \%$ of historic spawning substrate in the system has been established by resource managers as one part of the effort to delist the BUI for habitat in the HEC (E. Roseman pers. comm.)

From 2004 to 2012, three artificial reefs have been built in the HEC; the Middle Channel Reef(MCR) in the SCR, the Belle Isle Spawning Reef(BISR) and Fighting Island Reef (FIR) in the DR (Table 1). Post-construction assessment of fish response is essential to evaluate the effectiveness of artificial reef placement and fish use in this system.

Little is known about the early life history of lake sturgeon in the HEC, and only a few studies in the have specifically examined the larval phase of lake sturgeon in this system (Nichols et al. 2003, Roseman et al. 2011a). Comprehensive knowledge of larval lake sturgeon abundance, distribution, emergence, drift, growth, and survival is limited in this system, but is necessary to fully understand the response of lake sturgeon to artificially constructed spawning reefs. Primarily, this study investigated lake sturgeon egg deposition, larval abundance, seasonal and diel timing of emergence, growth, and vertical distribution in the water column near FIR in 2011-12. The relationship between substrate type and larval emergence was examined at FIR. In 2011-12, pre-reef construction and preliminary post-construction monitoring of lake sturgeon egg deposition and larval abundance near MCR were conducted. Additionally, larval lake sturgeon abundance, seasonal and diel timing of emergence, drift, growth, and vertical distribution in the water column were examined near NRC in 2010-12. The results of this study will provide information to managers, agencies, and constituents on ability of 
artificial reef structures provide conditions suitable for egg deposition, incubation, and larval emergence. This study will also help to build a more comprehensive understanding of the biology of lake sturgeon early life history in the HEC.

\subsection{METHODS}

\subsubsection{Study Sites}

In 2008, FIR was constructed in Canadian waters near the northeast shore of Fighting Island in the DR (Roseman et al. 2011a) (Figure 1, Table 1). FIR consists of 12 experimental reef beds containing four repeating substrate treatments (Roseman et al. 2011a) (Figure 1, Table 1). Prior to reef construction, investigations conducted by Boase and Kennedy (2008) did not find lake sturgeon spawning activity near the proposed reef site.

In 2012, MCR was constructed near the north end of the Middle Channel in the lower SCR (Figure 2) (Table 1). The reef consists of nine reef beds containing three repeating substrate treatments (Figure 2, Table 1).

The NCR is located in the North Channel of the lower SCR where lake sturgeon spawn on a bed of aged coal clinker (Baker 1980) (Figure 2, Table 1). The substrate and physical attributes of this site were characterized by Manny and Kennedy (2002).

\subsubsection{Egg Sampling}

During the spring season of 2010-12, egg mats were used to sample egg deposition and estimate egg density using methods and materials described by Roseman et al. (2011b). One egg mat gang consisted of three furnace filter egg mats. Weather and water conditions permitting, all egg mat gangs were retrieved on a weekly basis 
(Appendix B). Egg mats were inspected thoroughly, and all eggs were counted and removed. The clean egg mats were then re-deployed. Water depths at all egg mat sites can be found in Table 2 .

At FIR in 2011, one egg matt gang was deployed on each reef bed A-L from 1 April to 13 June, and at two upstream sites (2B \& 2C) from 11 April to 13 June (Figure 1, Appendix B). In 2012, one egg mat gang was deployed on each reef bed A-F and two downstream sites (4B \& 4C) from 24 April to 15 May, and two upstream sites ( $2 B$ \& 2 C) from 24 April to 11 May (Figure 1, Appendix B). The westernmost reef beds (I-L) were not sampled in 2012 because the substrate materials were covered by sand (G. Kennedy, pers. comm.).

In the lower SCR in 2010, 16 egg mat gangs were deployed from 14 April to 6 July (Figure 2, Appendix B). In 2011, 16 egg mat gangs were deployed from 12 April to 2 August (Figure 2, Appendix B). In 2012, 12 egg mat gangs were deployed from 28 March to 5 June (Figure 2, Appendix B).

\subsubsection{D-Frame Drift Net Larval Sampling}

D-frame drift nets were used to target emerging larval lake sturgeon following methods in Auer and Baker (2002) with modifications for deep water sampling found in Roseman et al. (2011b). The D-frame net specifications were described by Roseman et al. (2011b). Weather and water conditions permitting, D-frames were usually deployed at night from $\sim 20: 00$ to $\sim$ 06:00 hours, and retrieved on a $\sim 2$ hour cycle. D-frame samples were preserved in $95 \%$ ethanol. Flow measurements taken with General Oceanics, INC Model 2030R Mechanical Standard Rotor flow meters placed in the center of the net opening were unusable due to clogging by heavy vegetation and debris. In 
2012, water velocity readings were recorded with a Marsh McBirney Flo-Mate ${ }^{\mathrm{TM}}$ Model 2000 flow meter at all 2012 D-frame sites approximately $0.5 \mathrm{~m}$ above the river bottom, but not in the net opening.

At FIR in 2011, since lake sturgeon eggs were not detected, D-frame sampling occurred only on 6 and 7 June. Two nets were placed below each reef bed (A-D) and at two upstream sites (Table 4). At FIR in 2012, D-frame sampling was conducted biweekly from 15 May until 5 June. Sampling efforts were focused on reef beds A-D, where the highest egg densities were collected in 2012. Four nets were placed directly upstream (sites 1-4) of the reef beds and four were positioned directly downstream (sites 5-8) (Figure 3, Table 3).

At NCR in 2010, D-frame night sampling was conducted on 8, 9, and 29 June. On June 8 and 9, nets were sampled on an hourly basis from approximately 21:00 to 02:00 hours. On 29 June, sampling times were shortened to approximately 30 minutes due to an influx of Holopedium spp. Two nets were placed directly downstream of the reef, and two nets were placed approximately $0.18 \mathrm{~km}$ upstream in the North Channel (sites 1, 3-5) (Figure 4).

In the lower SCR in 2011, sampling efforts were focused on sites near NCR in the North Channel. Sampling locations were the same as 2010, with the addition of two nets placed approximately $1.4 \mathrm{~km}$ downstream of NCR (sites 8 \& 9) (Figure 4). Conditions permitting, sampling was conducted 3 nights per week from 13-30 June. Thereafter, sampling was reduced to one night per week until 13 July. Additionally, on 20 and 22 June, four nets were placed in the Middle Channel (sites 11-14) (Figure 4). 
In the lower SCR in 2012, weekly and biweekly D-frame sampling was conducted in the North Channel near NCR and in the Middle Channel near MCR, from 5 June to 2 July. In the North Channel, three of the 2011 sites were changed; the location of site 1 was moved to site 2 , and sites 4 and 5 were adjusted so one net sampled directly downstream of NRC, and one sampled directly upstream (sites 6 \&7) (Figure 4). Site 10 was added, but was only sampled on 13 June (Figure 4). In the Middle Channel, 2 nets were placed below MCR, and 2 nets were placed directly upstream (sites 15-18) (Figure 4). Reef construction was only partially completed at the time of sampling, and it was necessary to move sites 15 and $16 \sim 100 \mathrm{~m}$ downstream (sites $19 \& 20)$ (Figure 4). Day time D-frame drift sampling was conducted in the North and Middle Channels. In the North Channel, sites 2, 6, and 7 were sampled for 1-2 hours on 7, 11, 18, 22, 27 June \& 2 July, between $\sim$ 13:00-17:00 hours. In the Middle Channel, sites 19 and 20 were sampled on 7 June from approximately 14:00-19:30 hours.

\subsubsection{Depth-Stratified Larval Sampling}

Depth-stratified sampling was conducted in 2012, adapting a sampling design developed by D' Amours et al. (2011) in the Des Prairies River in Quebec, Canada. Onset Hobo Pendent light/temperature meters (Model: UA-002-6) were attached to conical nets at 0.5 meters below the surface, mid-depth, and 0.5 meters above the river bottom.

Downstream of FIR at site S-1, one string of six $30 \mathrm{~cm}$ conical nets was fished at depths of $0.5,1.0,3.5,4.0,7.0,7.5 \mathrm{~m}$ to assess vertical distribution of emerging and drifting larvae. To set the gear, a large trap net anchor was placed $30 \mathrm{~m}$ upstream of the sampling site. The trap net anchor was attached to $30 \mathrm{~m}$ of line, and a downstream 
cement anchor. The string of conical nets was attached to the cement anchor at the river bottom, and large buoy at the surface. Stratified sampling took place between $\sim 20: 00$ 03:00 hours and was conducted biweekly from 15 May until 4 June.

In the lower SCR one stratified sampling site S-1 was established in North Channel on the same nights as D-frame sampling (Figure 4). The sampling rig consisted of three $30 \mathrm{~cm}$ conical nets fished at depths of 1.0, 5.0, 9.5 meters and sampling took place between $\sim$ 20:00-06:00 hours. An additional site S-2 was sampled on 11 June at the same depth intervals as site S-1.

\subsubsection{Sampling Processing \& Larval Fish Identification}

All D-frame and stratified drift samples were preserved in 95\% ethanol. In 201112, larval samples collected in the St. Clair River were transported to USGS Great Lakes Science Center (GLSC) laboratory facilities in Ann Arbor, MI and stored at $4^{\circ} \mathrm{C}$ until processing. In compliance with the Convention on International Trade in Endangered Species of Wild Fauna and Flora (CITES) collection permits, samples collected from Canadian waters near FIR were transferred across the U.S.-Canada border following CITES chain of custody protocol. In 2011, samples collected near FIR were stored at Ontario Ministry of Natural Resources (OMNR) Lake Erie Management Unit facilities in Wheatley, ON until they were transferred to USGS GLSC facilities. In 2012, samples

collected near Fighting Island were stored at the University of Windsor Fisheries Ecology Laboratory in La Salle, ON. They were then moved to OMNR Lake Erie Management Unit facilities where they were processed, and the transferred to USGS GLSC facilities. All samples collected near FIR were stored at ambient room temperature. 
At the laboratory, all larval fish were removed from field sample bottles and stored in 95\% ethanol. Using a microscope and digital analysis software (Image Pro Plus), digital images of each larval lake sturgeon were recorded. We took images of multiple physical features and any physical abnormalities at three magnifications $(60 x, 120 x$, 250x). Total length (TL) was measured using image analysis software for each sturgeon larvae.

\subsubsection{Statistical Analysis}

SigmaPlot 12.3 statistical analysis software was used to perform linear regression analysis to examine the relationship between larval lake sturgeon TL and sampling date $(\alpha=0.05)$. This software was also used to perform a one-way repeated measures ANOVA, using substrate treatment and sampling date as the interaction terms $(\alpha=0.05)$.

To estimate the nightly timing of larval emergence, when a larval lake sturgeon was collected, the midpoint time between net deployment and retrieval times was binned into 4- 2 hour sampling periods in the DR; 20:00-21:59 hours, 22:00-23:59 hours, 24:002:00 hours, 2:00-4:00 hours. In the SCR, an additional sampling bin was added: 4:006:00 hours.

\subsection{RESULTS}

\subsubsection{Egg Deposition}

In 2011, sampling effort did not detect lake sturgeon eggs at FIR. Water temperatures were $1.4^{\circ} \mathrm{C}$ on April 1st, and reached $18^{\circ} \mathrm{C}$ by the end of the sampling period on 13 June. In 2012, eggs were collected from all substrate types (reef beds A-F) and $0.5 \mathrm{~km}$ downstream at site $4 \mathrm{~B}$ on 9 May; water temperature was $13.1^{\circ} \mathrm{C}$ (Figure 1 , Figure 5). Highest egg densities were collected from reef beds A-D ( $A=677 \mathrm{eggs} / \mathrm{m}^{2}$, 
$\mathrm{B}=587$ eggs $/ \mathrm{m}^{2}, \mathrm{C}=372$ eggs $\left./ \mathrm{m}^{2}, \mathrm{D}=233 \mathrm{eggs} / \mathrm{m}^{2}\right)$, and an average of $203 \mathrm{eggs} / \mathrm{m}^{2}$ were collected from all sites (Figure 1, Figure 5).

In 2010 in the lower SCR, lake sturgeon eggs were collected from NCR (site 13) on 26 May (186 eggs $\left./ \mathrm{m}^{2}\right), 2$ June $\left(286\right.$ eggs $\left./ \mathrm{m}^{2}\right)$, and 23 June $\left(18 \mathrm{eggs} / \mathrm{m}^{2}\right)$ when water temperatures were between $14.6-19.3^{\circ} \mathrm{C}$ (Figure 2, Figure 6). In 2011, the highest egg density of all three sampling years $\left(1722 \mathrm{eggs} / \mathrm{m}^{2}\right)$ was collected from NCR (site 13) on 8 June when the water temperature was $13.1^{\circ} \mathrm{C}$. On 14 June, a single egg $\left(4\right.$ eggs/ $\left.\mathrm{m}^{2}\right)$ was collected at this site when water temperatures were $13.3^{\circ} \mathrm{C}$ (Figure 2, Figure 6). In 2012, lake sturgeon eggs were collected from NRC (site 13) (50 eggs $/ \mathrm{m}^{2}$ ) (Figure 2, Figure 6) and from MCR (site 22) (222 eggs $/ \mathrm{m}^{2}$ ) on 30 May when water temperatures had reached approximately $15^{\circ} \mathrm{C}$ (Figure 2 ).

\subsubsection{Larval D-Frame and Depth-Stratified Sampling}

\subsubsection{Fighting Island Reef}

In 2011, sampling effort did not detect larval lake sturgeon. Water temperatures ranged between $18.5-19.4^{\circ} \mathrm{C}$ during the sampling period. In 2012,34 larvae $(14.9 \pm 3.9$ SD mm TL) were collected directly upstream and downstream of FIR. The majority of larvae $(91.2 \%)$ were collected from sites downstream of the constructed reef beds (Table 4). Approximately $44 \%$ of larvae were collected on 15 May, when water temperatures ranged from $14.6-15.1^{\circ} \mathrm{C}$ (Figure 7) Yolk sacs were present in 95\% of larvae collected on 15 and 17 May (Figure 8). Of the 21 larvae $(11.89 \pm 0.85 \mathrm{SD} \mathrm{mm}$ TL) collected on 15 and 17 May, $86 \%$ of individuals $(11.84 \pm 0.85 \mathrm{SD} \mathrm{mm}$ TL) did not have distinctive eye pigment, and 53\% of all larvae collected near FIR exhibited this characteristic (Figure 9). The majority of larvae (65\%) were collected between 20:00-00:00 hours (Figure 10). 
Linear regression analysis indicated a significant positive relationship between sampling date and average TL of individuals collected reef bed sites $\left(\mathrm{R}^{2}=0.995, \mathrm{DF}=5\right.$, $\mathrm{p}<0.001$ ) (Figure 7). Over the 15 day sampling period, larval lake sturgeon TL increased approximately $0.81 \mathrm{~mm} /$ day (Figure 7). A one-way repeated measures ANOVA found no significant difference in the larval lake sturgeon CPUEs (larval lake sturgeon/hr/sampling night) between the four sites (4-8) directly downstream of reef bed treatments A-D $(\mathrm{p}=0.241, \mathrm{DF}=27)($ Table 4$)$.

A total of two larval lake sturgeon were collected downstream of FIR in the stratified sampling gear at site S-1 when water temperatures ranged between $16.5-17.1^{\circ} \mathrm{C}$. One partial yolk sac larvae (16.72 mm TL) was collected on 21 May approximately $1.0 \mathrm{~m}$ below the surface. The other was a non-yolk sac larvae (18.17 mm TL) collected on 23 May approximately $0.5 \mathrm{~m}$ above the river bottom.

\subsubsection{Lower St. Clair River}

In 2010, 11 larval lake sturgeon $(18.86 \pm 1.11 \mathrm{SD}$ mm TL $)$ were collected from sites in the North Channel near NCR when the water temperature was $18.3^{\circ} \mathrm{C}$. Five larvae (18.4 $\pm 0.88 \mathrm{SD} \mathrm{mm} \mathrm{TL})$ were collected on 8 June; one had full yolk sac, two had partially absorbed yolk sacs, and two were non-yolk sac larvae. Six larvae $(19.25 \pm 1.20$ mm SD TL) were collected on 9 June; one had a full yolk sac and 5 were non-yolk sac larvae. Larval lake sturgeon CPUEs for all sampling nights ranged from $0-0.29$ sturgeon/hour and $64 \%$ of larvae were collected from sites $(1 \& 3)$ positioned upstream of NCR (Figure 4, Table 5).

In 2011, a total of 51 larval lake sturgeon $(19.07 \pm 1.95 \mathrm{SD} \mathrm{mm}$ TL$)$ were collected from the North Channel near NCR when water temperatures were between 
14.4- $16.5^{\circ} \mathrm{C}$ during the sampling period. Larvae were first detected at sites 3 and 8 on 17 June (Figure 4). Larvae were not collected from sites directly downstream of NCR until 20 June, when the highest CPUE (0.36 sturgeon/hour) from all North Channel sites combined was measured (Figure 11). Of larvae collected in the North Channel, 39\% were collected upstream of NCR (Table 5). Linear regression analysis indicated a significant positive relationship between sampling date and average total length of individuals collected in North Channel $\left(\mathrm{R}^{2}=0.903, \mathrm{DF}=4, \mathrm{p}=0.013\right)$ (Figure 11). Over 13 days of sampling, larval lake sturgeon TL increased $0.34 \mathrm{~mm} /$ day. Full yolk sacs were present in 9 larvae, $78 \%$ of which were collected from sites located downstream of NCR. Additionally, three lake sturgeon larvae were collected from the Middle Channel at site 11 (Figure 4, Table 5). Two of these larvae $(19.01 \pm 2.35 \mathrm{~mm} \mathrm{TL})$ were collected on 20 June when the water temperature was $16.7^{\circ} \mathrm{C}$; one was a non-yolk sac larvae, and one had a partially absorbed yolk sac. The other larvae ( $16.57 \mathrm{~mm} \mathrm{TL})$ had a partially absorbed yolk sac and was collected on 22 June when the water temperature was $16.1^{\circ} \mathrm{C}$.

In 2012, a total of 81 lake sturgeon larvae $(19.15 \pm 2.13 \mathrm{SD}$ mm TL $)$ were collected from the North Channel when temperatures were between $14.5-17^{\circ} \mathrm{C}$. Larvae were first collected from sites $2,3,6$, and 8 on 5 June. Of these larvae, $79 \%$ were collected from sites 2, 3, and 6, all of which are sites upstream of NCR (Figure 4, Table 5). The highest CPUE (0.93 sturgeon/hour) of all North Channel sites combined was collected on this night (Figure 12, Table 5). Of all larvae collected in the North Channel, $60 \%$ were collected from sites upstream of NCR (Table 5). Linear regression analysis did not show a significant relationship between sampling date and average total length of larvae collected from the North Channel $\left(\mathrm{R}^{2}=0.128, \mathrm{DF}=4, \mathrm{p}=0.555\right)$ (Figure 12). Full 
yolk sacs were present in 14 larvae, $71 \%$ of which were collected from the site 7 positioned directly downstream of NCR (Figure 4). On 5 June, one yolk sac larvae $(13.53 \mathrm{~mm} \mathrm{TL})$ was collected from site 6 that did not have distinct eye pigment.

In 2012, 35 larvae (19.45 $\pm 1.67 \mathrm{SD}$ mm TL) were collected from the Middle Channel near MCR, when water temperatures ranged from $14.5-16.8^{\circ} \mathrm{C}$ (Table 5). The highest CPUE (0.95 sturgeon/hr) was detected on 19 June (Figure 13). Linear regression analysis did not detect a significant relationship between sampling date and average total length of larvae collected from the North Channel $\left(\mathrm{R}^{2}=0.375, \mathrm{p}=0.58\right)$ (Figure 13). The majority of larvae $(60 \%)$ were collected from sites positioned of upstream MCR, and full yolk sacs were present in 2 larvae (Table 5).

Lake sturgeon larvae were not collected during day time sampling or in any depth stratified samples. In 2010, all larvae were collected between 21:00 and 02:00. In 2011, the majority of larvae were collected between 24:00 and 2:00 hours, and in 2012 the majority of larvae were collected between 2:00 and 4:00 hours (Figure 14).

\subsection{DISCUSSION}

It is well established that loss of spawning habitat or access to spawning habitat is detrimental to sturgeon populations (Rochard 1990, Auer 1996, Daugherty et al. 2008). To address this problem, various agencies and groups have constructed or enhanced sturgeon spawning habitat in multiple American, Canadian, and Russian river systems (Khoroshko and Vlasenko 1974, Johnson et al. 2006, Dumont et al. 2011, Roseman et al. 2011a). These restoration projects have demonstrated varying degrees of success in terms of short and long term post-construction lake sturgeon use. A literature review by 
Kerr et al. (2011) summarized that coarse substrate material, and clean interstitial spaces within the substrate are often present in successful construction projects. There is evidence that historic channelization of the HEC reduced the amount of coarse substrate available for spawning, a problem the artificial reefs were created to alleviate. Monitoring of sturgeon response to artificially constructed or enhanced spawning grounds is critical to the process of establishing and refining construction methods, materials and conditions that satisfy life history requirements for sturgeon.

\subsubsection{Fighting Island Reef}

This study found that lake sturgeon continue to use FIR as a spawning ground, and viable eggs and larvae were collected from constructed reef bed sites. Lake sturgeon eggs were first collected from the reef beds in 2009, one year after reef construction, and again in 2010 (Roseman et al. 2011a). Lake sturgeon larvae (7 individuals) were first collected in 2009, and larval sampling was not conducted in 2010 (Roseman et al. 2011a). Sampling conducted in this study did not result in the collection of lake sturgeon eggs or larvae in 2011. If spawning did occur, it is possible that larval emergence was missed because the water temperature had already reached $\sim 19^{\circ} \mathrm{C}$ when larval sampling began, which was $\sim 4^{\circ} \mathrm{C}$ warmer than when the majority of drifting larvae were collected in 2012 , and sturgeon are known to spawn at $10-15^{\circ} \mathrm{C}$ (Kempinger 1988, Auer and Baker 2002).

In 2012, average egg density was estimated to be $203 \mathrm{egg} / \mathrm{m}^{2}$ near FIR. These density estimates were higher than egg densities reported by Roseman et al. (2011a) in $2009\left(102 \mathrm{eggs} / \mathrm{m}^{2}\right)$ and $2010\left(12 \mathrm{eggs} / \mathrm{m}^{2}\right)$. While an increase in estimated egg density in 2012 is an encouraging result, this does not necessarily mean there was a higher 
incidence of adult spawning activity. Since the egg sampling method used in the HEC presents only a weekly snapshot of total sturgeon egg deposition each season, more intensive sampling would provide better estimates of egg density and spatial distribution. In this case, sampling effort was balanced with logistical constraints, and the need to minimize disturbance to spawning adults.

In 2012, larval emergence downstream of each substrate type was documented, but a significant difference in CPUE (sturgeon/hr) of larval sturgeon between the four substrate types (reef beds A-D) was not observed. It is possible that adult lake sturgeon do not exhibit a spawning substrate preference between these reef materials, or that some condition or combination of conditions such as depth, slope, water velocity, or where spawned eggs physically settle have a stronger influence over where the highest larval emergence occurs. The power of this analysis was reduced due to sedimentation of the western reef beds, eliminating adult sturgeon spawning on those substrate replicates, which reduced our ability to detect substrate preference. Interestingly, the spatial pattern of larval emergence did not follow the egg density pattern. The lowest larval CPUE value was collected from the shallowest reef bed (A), which had the highest egg densities, and higher CPUE values were detected directly downstream of the deeper reef beds B-D, which had lower egg densities.

In this study, a high proportion (53\%) of emerging lake sturgeon yolk sac larvae collected in 2012 did not have distinctive eye pigment. Of the 21 larvae $(11.89 \pm 0.85$ SD mm TL) collected on 15 and 17 May, 86\% of individuals (11.84 \pm 0.85 SD mm TL) did not have distinctive eye pigment. These larvae were similar in appearance to an image published by Harkness and Dymond (1961) of a newly hatched larval lake 
sturgeon. Additionally, the lack of eye pigment characteristic observed in this study was similar to images of newly hatched larvae of green sturgeon (Acipenser medirostris) and white sturgeon (Acipenser transmontanus) that had been reared in hatchery facilities (Deng et al. 2002, Wang et al. 2006). This indicates the likelihood that the emerging larvae collected in this study had hatched very recently. This result is concerning, as it is well established that after hatching, lake sturgeon larvae typically spend a several days in the substrate while their yolk sacs are absorbed before they emerge and drift downstream (Kempinger 1988, LaHaye et al. 1992, Auer 1996, Auer and Baker 2002). Additionally, while the lack of eye pigment in emerging and drifting lake sturgeon larvae may be present in other systems, it is not commonly reported.

Potentially, excessively fast water velocities could flush larvae from the substrate prematurely; however, the water velocities measured near FIR on 8 June $(0.48-0.70 \mathrm{~m} / \mathrm{s})$ fell within the range of water velocities at measured at known spawning sites in the HEC (Manny and Kennedy 2002). Additionally, lack of eye pigment was detected in one larval sturgeon collected from the lower SCR, where water velocities measured on 19 and 15 June were considerably slower than those measured near FIR (Table 5). Furthermore, these velocities were also similar to the water velocities measured near artificial spawning sites in other rivers where egg deposition has been confirmed; the St. Lawrence River $(0.52 \& 0.60 \mathrm{~m} / \mathrm{s})($ Johnson et al. 2006) and the Des Prairie River $(1.0 \mathrm{~m} / \mathrm{s})$ (Dumont et al. 2011).

It is also a possibility that larvae lacking eye pigment were prematurely forced from their eggs. Studies in the Volga River, Russia found that the ability of the egg membrane or chorion to resist rupturing varies among sturgeon species based on their 
spawning locations; essentially sturgeon eggs deposited at upstream locations were more resistant to rupturing than the species that spawn further downstream (Nikolsky 1963 as cited in Auer 1996). It is possible that the adults that spawned on the reef in 2012 may have been better adapted to some other area in the system that has different environmental conditions. However, the conditions at this site are similar to other known spawning sites in the HEC in terms of depth, water velocity and water temperature (Manny and Kennedy 2002, Nichols et al. 2003, Caswell et al. 2004). Additionally, Goodyear et al. (1980b) provided evidence of historic spawning near FIR

Larvae lacking distinct eye pigment were collected downstream of all four substrate types. This suggests that a particular substrate type did not provide better or worse conditions for developing eggs/larvae, in terms of providing adequate interstitial spaces, places for eggs to adhere, or current refuge. Further research should be done to assess viability and fate of these larvae that may to be emerging, or forced out prematurely from the substrate, and the factors leading to this unusual occurrence.

\subsubsection{Lower St Clair River}

In 2010-12, this study found that lake sturgeon continue to use NCR as a spawning ground, and viable eggs and larvae were collected near this site. Lake sturgeon eggs and larvae were first detected near NCR by Nichols et al. (2003). In 1998, these authors estimated the average egg density on the reef to be $2084 \mathrm{eggs} / \mathrm{m}^{2}$ and collected a total 31 larvae and in 1999, they estimated the average egg density to be 2958 eggs $/ \mathrm{m}^{2}$ and collected six live larvae and 23 dead larvae. In 2010-12, the average yearly estimates of egg density were lower than those estimated by Nichols et al. (2003); these 
authors employed a more intensive sampling regime, and it is possible that 2010-12 egg densities are underestimated.

In 2010-12, we collected larvae upstream of NRC in the North Channel. This result indicates that lake sturgeon could be spawning at additional locations that have not yet been identified; however our egg mat sampling network has not detected additional spawning sites. Another possibility is that these larvae drifted from the Blue Water Bridge spawning grounds located near the headwaters of the SCR approximately $65 \mathrm{~km}$ upstream. However, since we do not know the exact timing of adult spawning and larval emergence at this site, we are unable to determine if larvae originated from the Blue Water Bridge site. To sample for larval sturgeon using D-frames at this site is not feasible due to heavy shipping traffic, however, scuba surveys would be helpful to investigate the timing of adult spawning and larval emergence.

In 2011, prior to reef construction in the Middle Channel, sampling efforts did not result in egg collection; however, 2 of the 3 larvae collected there had partial yolk-sacs. This result suggests that spawning either occurred in the Middle Channel undetected, or there are additional unknown spawning sites in close proximity upstream. It is unlikely that if the larvae collected in the middle channel originated from the Blue Water Bridge site that they would still have yolk sacs by the time they drifted $\sim 65 \mathrm{~km}$ to our sampling sites, providing further evidence that larvae are originating from additional unidentified spawning grounds closer to the Middle Channel.

In 2012, at MCR, egg deposition was first detected by USGS SCUBA divers on 25 May, before reef construction was completed in the Middle Channel (Greg Kennedy, USGS, pers. comm.). Eggs were collected on egg mats for the first time on 30 May. 
This is an encouraging result; egg deposition had not been detected in the Middle Channel for two spawning seasons prior to reef construction. Interestingly, the majority $(60 \%)$ of larvae were collected from sites positioned directly upstream of the newly constructed spawning reefs, again suggesting that larvae are originating from unidentified spawning locations upstream. Larvae collected upstream of the reef were an average of $19.63 \pm 1.76 \mathrm{~mm}$ TL . This size is approximately $5 \mathrm{~mm}$ smaller than larvae collected by Auer and Baker (2002) 61 river km downstream of the spawning ground in the Sturgeon River, Baraga County, MI, suggesting it is probably not likely that they originated from the Blue Water Bridge spawning grounds, located $\sim 65 \mathrm{~km}$ upstream. The ability to pinpoint the start of egg deposition at the Blue Water Bridge spawning grounds, and a more extensive egg mat sampling network in the lower could help to identify the origins of these larvae.

\subsubsection{Diel Timing of Larval Emergence}

This study detected the majority of larval lake sturgeon emergence and drift occurred between 20:00 and 04:00 hours in the HEC. While sampling effort did not encompass an entire 24 hour period, larval emergence or drift was not detected during any day time sampling. These results are in agreement with many studies in other systems that have found that the majority of emergence and drift occurs between dusk and dawn. (Kempinger 1988, D’Amours 2001, Smith and King 2005, Johnson et al. 2006, Dumont et al. 2011).

\subsubsection{Depth Stratified Larval Sampling}

In 2012, only 2 lake sturgeon larvae were collected in depth-stratified sampling gear; 1 larvae was collected from $1 \mathrm{~m}$ above the river bottom, and the other was detected 
$1 \mathrm{~m}$ below the water's surface. With such a small sample size it is difficult to characterize these results. While it is interesting that a larvae was collected near the surface at a place of $8.5 \mathrm{~m}$, further study is need to determine if this is the result of larval sturgeon behavior, dying or weak larvae, disturbance, or random variation. Larval lake sturgeon were not detected in depth-stratified sampling gear in the SCR. Depth-stratified effort was considerably less than D-frame sampling effort, which may have contributed to the small sample sizes.

\subsubsection{Future Work}

Near FIR, future monitoring should include assessing the survival of emerging larvae that do not have distinct eye pigment. Additionally, throughout the HEC, it will be important to estimate the number of adults involved in spawning on the artificial reefs. This type of data is lacking in HEC at both natural spawning sites and artificial reef sites. This is important because it is possible that attracting lake sturgeon to artificial reefs could disperse the spawning adults too much, and actually be detrimental to reproductive success. This study identified the likelihood of additional uncharacterized spawning sites in the St. Clair River. It will be important to try and identify these sites by using scuba surveys or extending the egg mat sampling network.

\subsubsection{Conclusions}

These results provide further evidence that introducing artificial reef materials in the HEC can attract adult lake sturgeon spawning activity, and provide conditions suitable for egg deposition, incubation, and larval emergence. The construction methods and materials, and site conditions used in these projects can be used to inform future spawning habitat restoration or enhancement efforts. This study has also identified the 
likelihood of additional uncharacterized natural spawning sites between the known sites in the lower SCR and the Blue Water bridge spawning site. 


\subsection{ABSTRACT}

Lake sturgeon (Acipenser fulvescens) are known to spawn on coal clinker, a waste material produced by coal combustion, in the Huron-Erie Corridor (HEC). Although coal clinkers are chemically inert, some trace elements can be reincorporated with the clinker material during the combustion process. Since lake sturgeon eggs and larvae are developing in close proximity to this material, it is important to measure the concentration of potentially toxic trace elements. This study focused on arsenic, which occurs naturally in coal and can be toxic to fishes. A laboratory experiment was conducted to measure total arsenic concentration in samples taken from four substrate treatments submerged in distilled water; limestone cobble, rinsed limestone cobble, coal clinker, and rinsed coal clinker. Samples were taken at three time intervals: 24 hours, 11 days, and 21 days. ICP-MS analysis showed that concentrations of total arsenic were below the EPA drinking water standard (10ppb) for all samples. However, at the 24 hour sampling interval, a two way repeated measures ANOVA with a Holm-Sidak post hoc analysis $(\alpha=0.05)$ showed that the mean arsenic concentration was significantly higher in the coal clinker substrate treatment then in the rinsed coal clinker treatment $(\mathrm{p}=0.006)$, the limestone cobble treatment $(\mathrm{p}<0.001)$, rinsed limestone cobble treatment $(\mathrm{p}<0.001)$ and the control $(\mathrm{p}<0.001)$ Additionally, mean arsenic concentration was significantly higher in the rinsed coal clinker treatment than the limestone cobble treatment $(\mathrm{p}=0.001)$, the rinsed limestone treatment $(\mathrm{p}=0.009)$ and the control $(\mathrm{p}=0.002)$. While the effects of specifically exposing developing lake sturgeon to arsenic remain unstudied, the concentrations of total arsenic measured in this study are orders of magnitude lower than the EPA standards for fresh water aquatic life. 


\subsection{INTRODUCTION}

Lake sturgeon (Acipenser fulvescens) are known to spawn on coal clinker/bottom ash (referred to as "coal cinder" by other sources) at two locations in the Huron-Erie Cooridor (HEC) (Manny and Kennedy 2002, Nichols et al. 2003, Caswell et al. 2004) . One spawning site is in the North Channel of the lower St. Clair River (SCR) where

clinkers were deposited by coal powered steamships at the turn of the $19^{\text {th }}$ century (Baker 1980). The other site is near Zug Island in the Detroit River (DR). In 2004, coal clinkers were used as a substrate material in the construction of the Belle Isle Spawning Reef in the DR (Read and Manny 2006).

Coal clinkers are an unreactive waste material produced by coal combustion. The chemical content of clinkers depends on the source of the parent coal, but is usually composed of silicon dioxide $\left(\mathrm{SiO}_{2}\right)$, iron oxide $\left(\mathrm{Fe}_{2} \mathrm{O}_{3}\right)$, and aluminum oxide $\left(\mathrm{Al}_{2}\right.$ $\mathrm{O}_{3}$ ) (Benson a Bradshaw 2011). Goodarzi et al. (2011) established a class of trace elements found in coal including arsenic, nickel, lead, and sulfur that can volatilize when heated and then can condense within the combustion system. These trace elements can become reincorporated with the clinker material (Goodarzi 2011). Since lake sturgeon eggs and larvae are developing in close proximity to this material, it is important to measure the concentration of potentially toxic trace elements.

The trace element examined in this study was arsenic, which occurs naturally in much of the world's coal. Arsenic was chosen for analysis because fishes are known to be sensitive to acute and chronic exposure to arsenic, which can cause suffocation, gill damage, liver damage, and physical abnormalities (Sorenson 1991, Irwin 1997). The objective of this study was to measure the concentration of total arsenic sampled from 
actual artificial reef building materials (coal clinkers, limestone cobble) submerged in distilled water over a 21 day period. We predicted that higher concentrations of total arsenic would be present in the coal clinker treatments. We also examined if first removing fine particulate matter by rinsing substrates with distilled water effected the concentration of arsenic in each substrate treatment. We predicted that higher concentrations would be present in the coal clinker treatment than the rinsed coal clinker treatment.

\subsection{METHODS}

Substrate treatments were submerged in distilled water and sampled at three time intervals: 24 hours, 11 days, and 21 days. These time intervals approximately mimic what developing lake sturgeon would encounter at 24 hours after egg deposition, hatch (11 days) and emergence (21 days). Ideally, flowing water would have been run over substrates to simulate river-like conditions, but for this preliminary analysis the objective was only to determine if arsenic concentrations were present at detectable levels. There were three replicates of each substrate treatment; Limestone cobble, rinsed limestone cobble, coal clinkers, and rinsed coal clinkers (Table 6).

Fifteen cylindrical glass jars $(2.84 \mathrm{~L})$ with lids were washed with $10 \% \mathrm{HCL}$ solution, then rinsed 6 times with distilled water. Approximately $1.8 \mathrm{~kg} / 1.73 \mathrm{~L}$ of limestone cobble were placed into 6 of the jars ( 3 rinsed, 3 not rinsed). Approximately $680 \mathrm{~g} / 1.73 \mathrm{~L}$ of modern coal clinkers were placed into 6 of the jars (3 rinsed, 3 not rinsed). The remaining 3 jars were filled with $1.5 \mathrm{~L}$ of distilled water and served as controls. For "rinsed" treatments, weighed quantities of substrate $(1.8 \mathrm{~kg}$ limestone cobble, $680 \mathrm{~g}$ modern coal boiler slag) were placed on a fiberglass screen. Substrates 
were rinsed with approximately $7.5 \mathrm{~L}$ of distilled water, and gently agitated. The screen was washed with $10 \%$ HCL solution, and then rinsed with distilled water between each replicate.

After substrates were placed in jars, $1.5 \mathrm{~L}$ of distilled water was added. Jar lids were sealed with parafilm. Jars were exposed to ambient room temperature $\left(19-20^{\circ} \mathrm{C}\right)$ and were generally kept in darkness. After approximately 24 hours, $15 \mathrm{ml}$ water samples were transferred with disposable 10 and $5 \mathrm{ml}$ pipette tips and pipette aid to acid-washed Erlenmeyer flasks. Immediately after sampling, a vacuum pump was used to filter each sample through Watman no.1 filter paper $(7 \mathrm{~cm})$ placed in a Buchner funnel. Filtered samples were transferred to $50 \mathrm{ml}$ falcon tubes, digested with $0.015 \mathrm{ml}$ of nitric acid and then stored at $-80^{\circ} \mathrm{C}$. This process was repeated on 16 and 26 April 2012 for a total of 45 water samples. Water samples were analyzed for total arsenic content using ICP-MS U.S. Environmental Protection Agency (EPA) Method 200.8 by Whitewater Associates in Amassa, MI on 6 February 2012.

\subsubsection{Statistical Analysis}

SigmaPlot 12.3 statistical analysis software was used to perform a 2-way repeated measures ANOVA, using substrate treatment and sampling date as the interaction terms $(\alpha=0.05)$. The Holm-Sidak method was used for post-hoc analysis $(\alpha=0.05)$.

\subsection{RESULTS}

Total arsenic levels were below the EPA drinking water standard (10 ppb) for all samples (Table 7). A 2-way repeated measures ANOVA found statistically significant differences between mean arsenic concentration in substrate treatments $(p=0.004, D F=4)$, 
mean arsenic concentration by date $(\mathrm{p}=0.007, \mathrm{DF}=2)$, and a significant treatment date interaction $(\mathrm{p}<0.001, \mathrm{DF}=8)($ Table 8$)$.

Holm-Sidak post-hoc analysis found that within the coal clinker treatment, there were statistically significant differences in mean arsenic concentration between the mean concentration at 24 hours, and the mean concentration at both $11(\mathrm{p}<0.001)$, and 21 days $(\mathrm{p}<0,001)$ (Figure 15). This post-hoc analysis also found within the rinsed coal clinker treatment there were statistically significant differences in mean arsenic concentration between the mean concentration at 24 hours, and the mean concentration at both 11 $(\mathrm{p}=0.001)$, and 21 days $(\mathrm{p}<0,001)$ (Figure 16).

At the 24 hour sampling interval, this post hoc analysis showed that the mean arsenic concentration was significantly higher in the coal clinker substrate treatments then in the rinsed coal clinker treatment $(p=0.006)$, and the limestone cobble treatment $(p<0.001)$, the rinsed limestone cobble treatment $(p<0.001)$ and the distilled water control $(\mathrm{p}<0.001)$ (Table 3). Additionally, mean arsenic concentration was also significantly higher in the rinsed coal clinker substrate treatment than the limestone cobble treatment $(\mathrm{p}=0.001)$ the rinsed limestone treatment $(\mathrm{p}=0.009)$ and the distilled water control $(\mathrm{p}=0.002)$

These differences were not observed at the 11 day and 24 hour sampling interval, except for one pair at the 11 day sampling period where the mean total arsenic concentration of the rinsed limestone cobble was significantly larger that the distilled water control $(\mathrm{p}=0.008)$. 


\subsection{DISCUSSION}

As predicted, mean concentration of total Arsenic was significantly higher in both the coal clinker and rinsed coal clinker treatments than in the limestone and rinsed limestone treatments, and distilled water control. Additionally, as expected, mean concentration of total Arsenic was higher in the coal clinker treatment than in the rinsed coal clinker treatment. Most concentrations of total arsenic were only slightly above the

detectable limit, and all water samples would be considered safe for human consumption in terms of total arsenic concentration. Additionally, EPA guidelines recommend that levels of acute exposure for fresh water organisms to arsenic should be below $340 \mathrm{ppm}$ and levels of chronic exposure should be below $150 \mathrm{ppm}$, which are several orders of magnitude larger than the concentrations measured in this study (EPA 1995)

Furthermore, because arsenic was measured as total arsenic, it is unknown what form(s) of arsenic were present in the samples. Primarily, there are two forms of arsenic present in water; arsenite (As+3) and arsenate (As+5) (Irwin 1997). Generally, As+3 exposure is more toxic to living organisms (Sorenson 1991, Irwin 1997). Future work should consider employing arsenic speciation analysis to get a better understanding of toxicity risks.

Mean total arsenic concentration decreased over time in both the coal clinker and rinsed coal clinker treatments. This is likely because arsenic/arsenic compounds are heavier than water and are accumulating at the bottom of the jar. Allowing arsenic contaminated water to remain undisturbed for periods of time is actually a process called sedimentation and has been studied in the past as a potential method of treating arsenic 
contaminated drinking water in rural areas of developing countries (Han et al. 2002, Ahmed et al. 2001).

Future work should include methods for either a flowing water system to mimic actual river conditions, or water agitation such as an aquarium bubbler, periodic stirring of the substrate, or agitating the substrate before taking samples. Additionally, water samples should be taken from the interstitial spaces of the substrate treatments. In natural systems, lake sturgeon eggs often settle in interstitial spaces, and larvae remain here for several days after hatching (Kempinger 1988, LaHaye et al. 1992, Auer 1996, Auer and Baker 2002). Sampling from interstitial spaces in the substrate better simulate what materials developing lake sturgeon eggs and larvae would potentially be in contact with. 


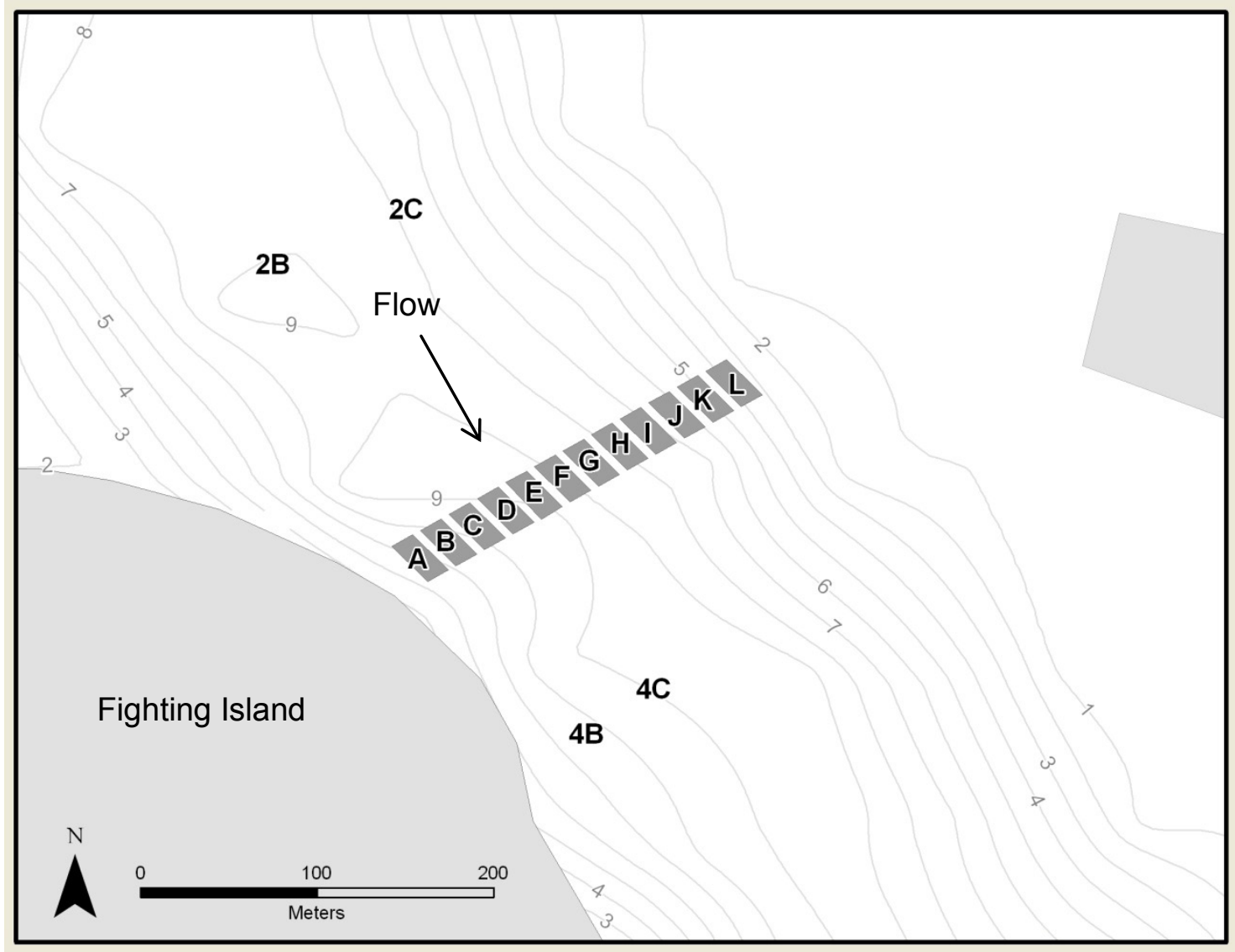

Figure 1: 2011-12 egg mat sampling sites near/on FIR in the DR. Sites A-L and sites 2B and 2C were sampled in 2011. Sites A-F and site 2B, 2C, 4B, and 4C were sampled in 2012. 


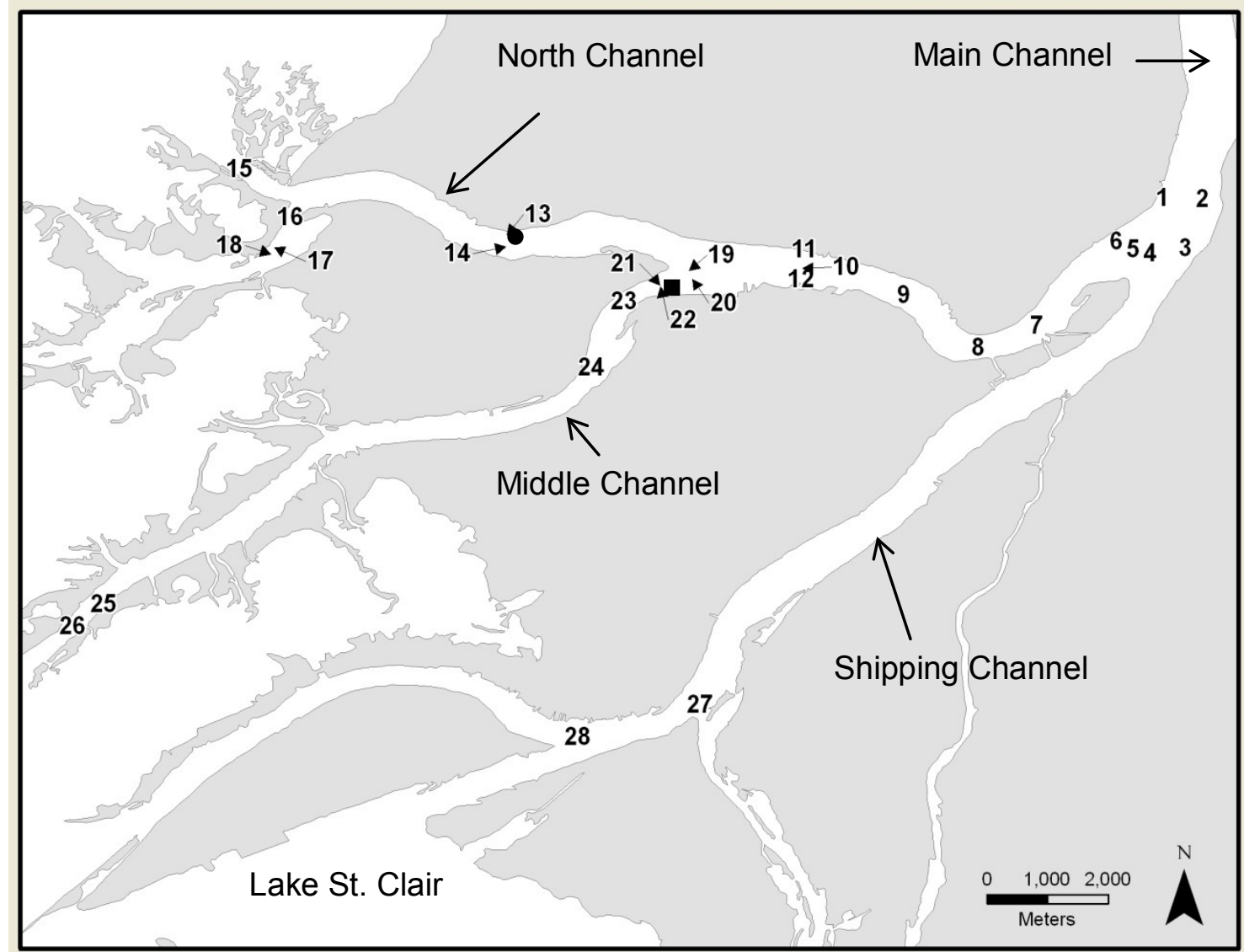

Figure 2: 2010-12 Egg mat sites in the lower St. Clair River. The black circle represents NCR and the black square represents MCR. 


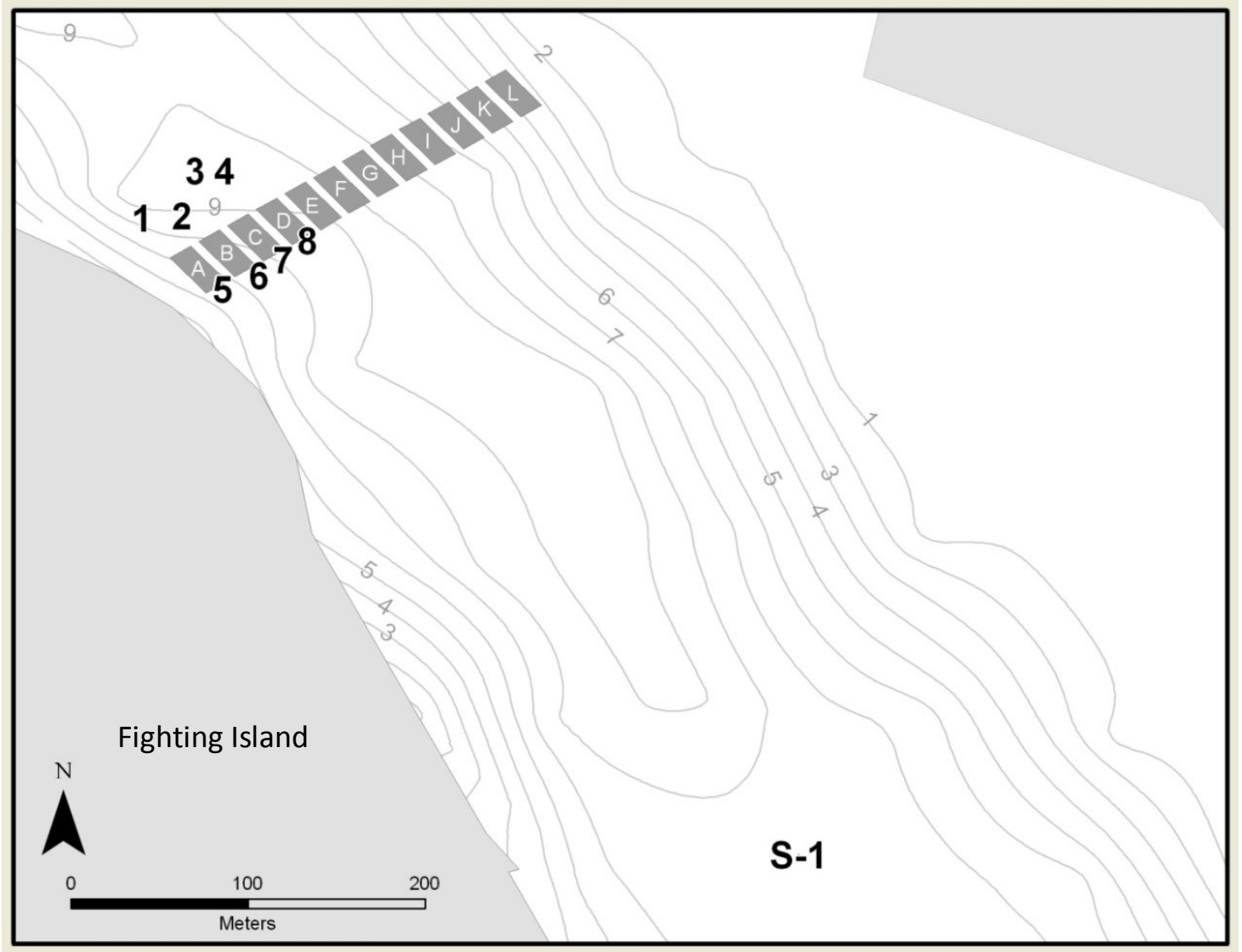

Figure 3: D-frame and depth-stratified larval sites near FIR in the DR in 2012. Sites 1-8 are D-frame sites and site $\mathrm{S}-1$ is a depth-stratified site. 


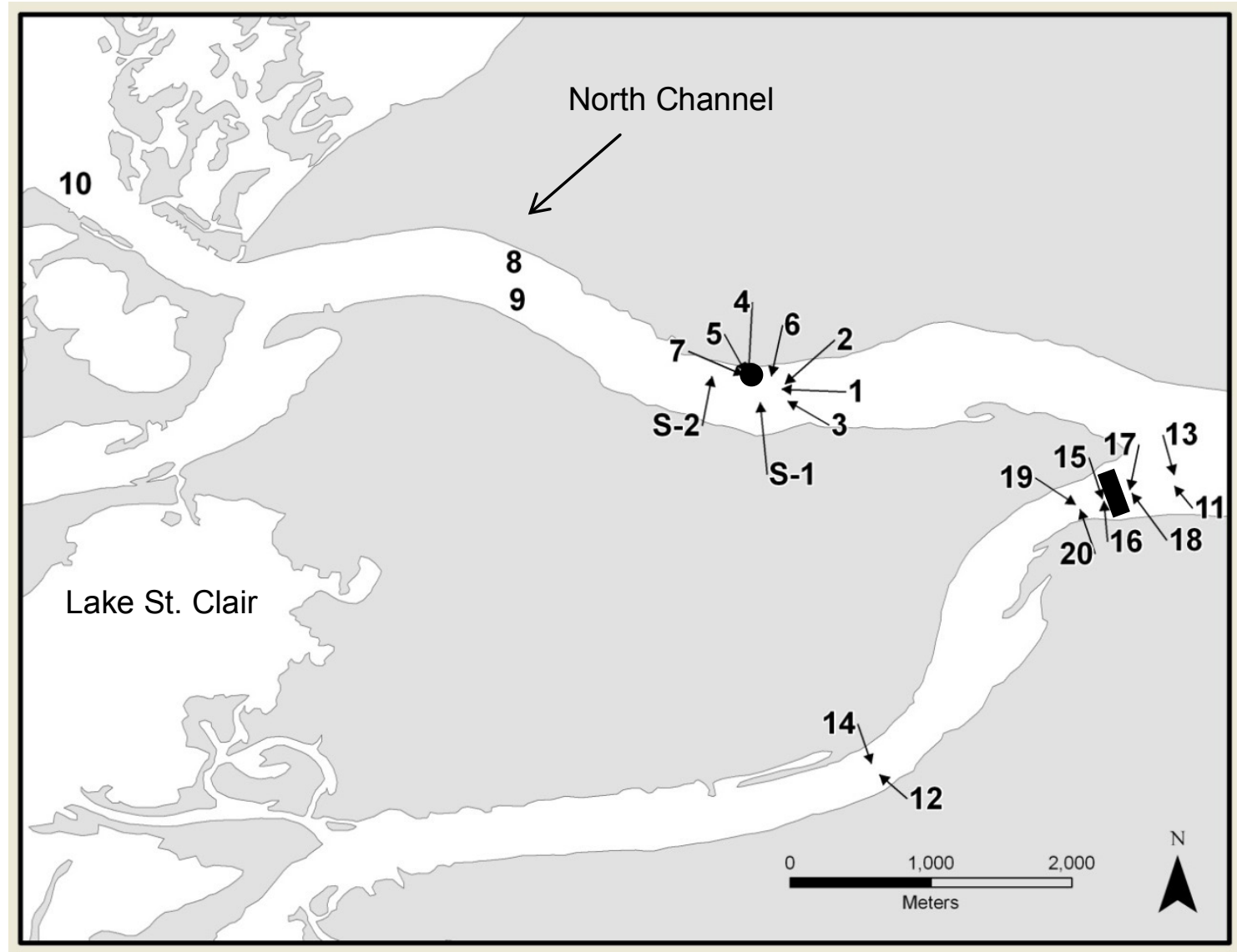

Figure 4: D-frame and depth-stratified larval sites near in the North Channel and Middle Channel of the lower SCR. Sites S-1 and S-2 are stratified sites. The black circle represents NCR and the black rectangle represents MCR. 


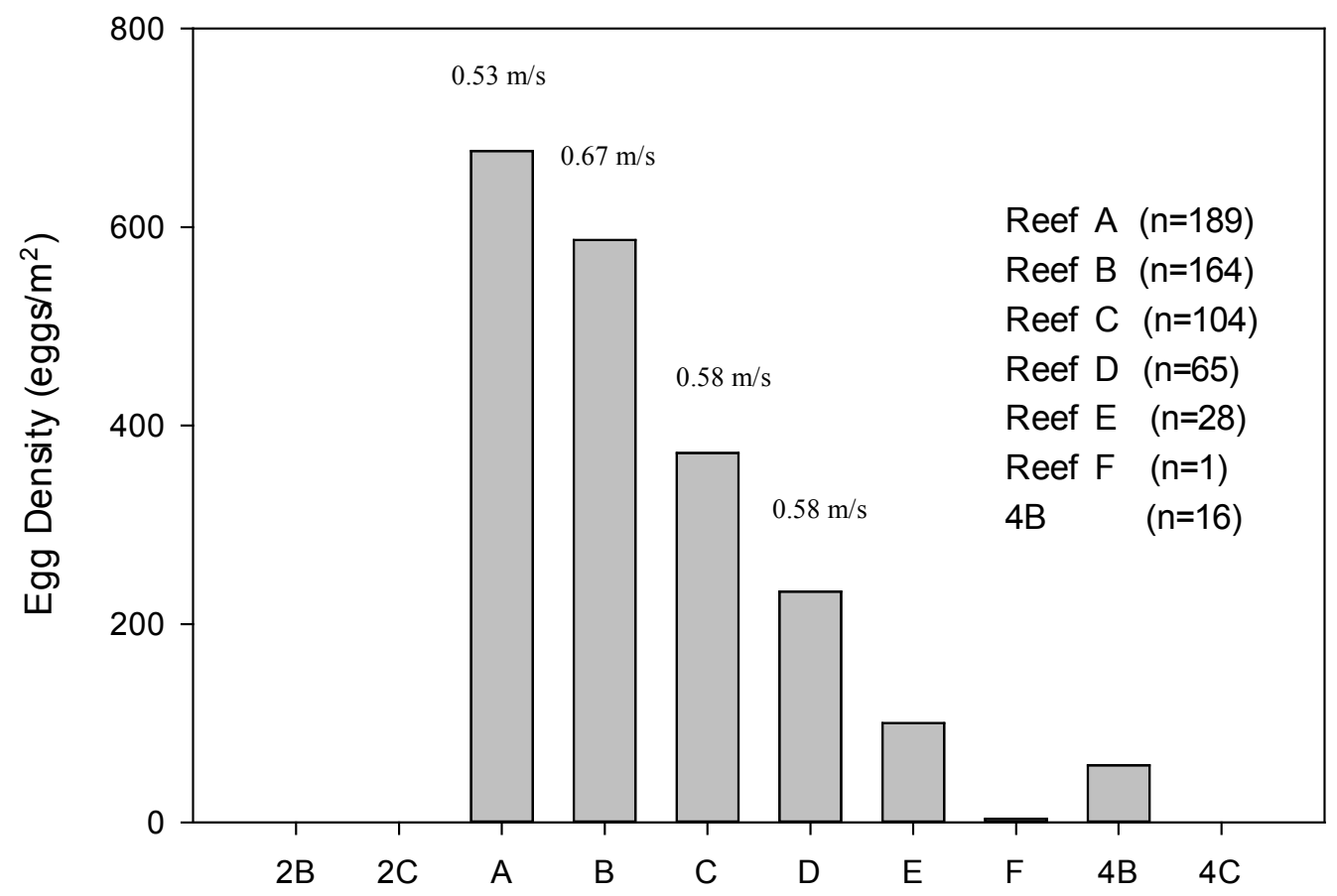

Egg Mat Site

Figure 5: Lake sturgeon egg densities $\left(\mathrm{eggs} / \mathrm{m}^{2}\right)$ at egg mat sites near/on FIR in the DR on 9 May 2012. Water velocity was measured with a Marsh McBirney Flo-Mate ${ }^{\text {TM }}$ Model 2000 flow meter directly upstream and downstream of each reef bed (A-D) on 8 June, 2012. On the figure, an average of the upstream and downstream water velocities are shown. 


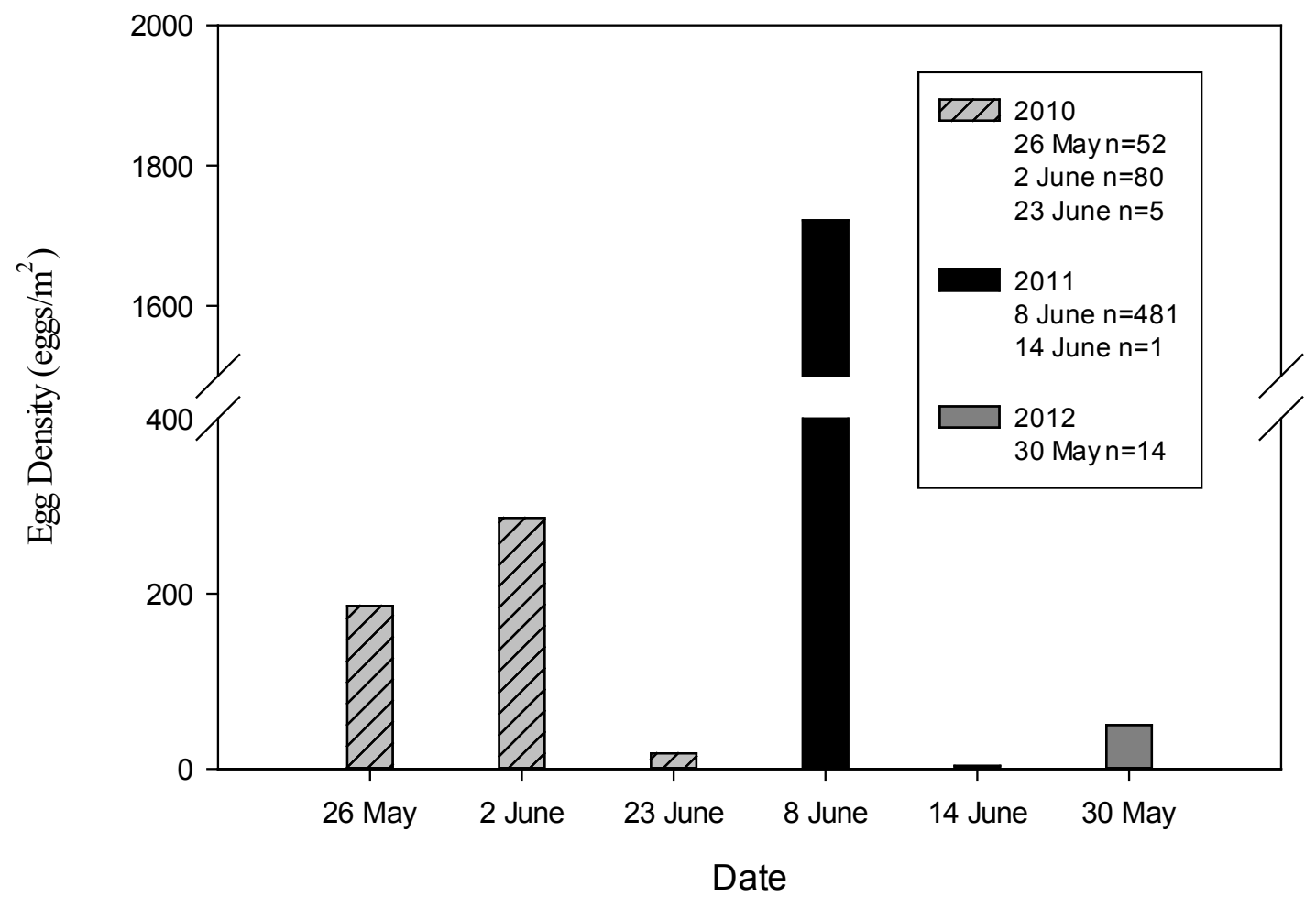

Figure 6: Lake sturgeon egg densities $\left(\mathrm{eggs} / \mathrm{m}^{2}\right)$ on the NCR (egg mat site 13) in the North Channel of the lower SCR in 2010-2012. "n" indicates total number of eggs collected at each egg mat site. 


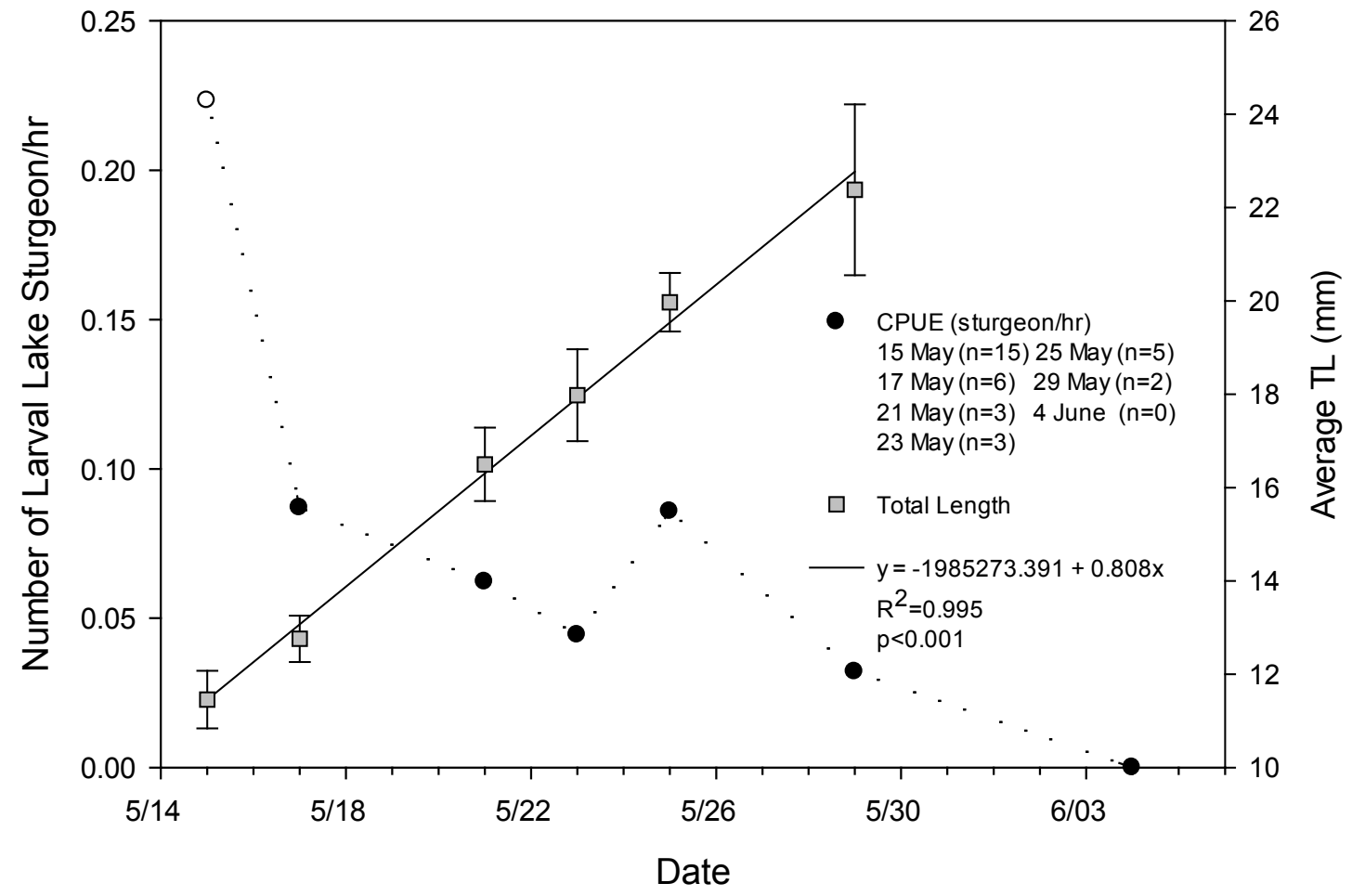

Figure 7: Larval lake sturgeon CPUE (sturgeon/hr) and TL \pm (SD) by sampling date near FIR in the DR in 2012. On 15 May, for the TL plot, $n=12$ because 3 individuals were too damaged to obtain a TL measurement. 


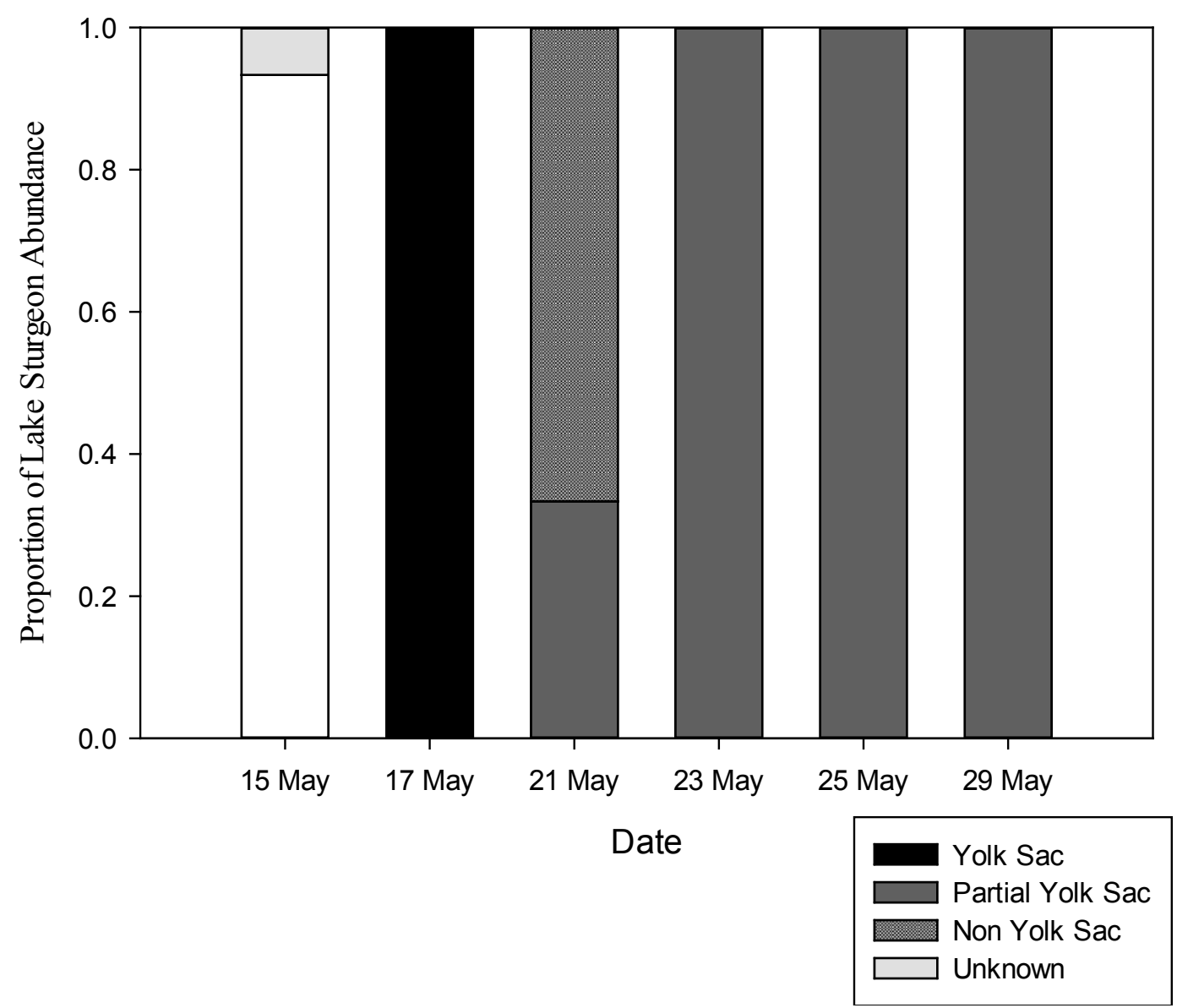

Figure 8: Proportion of larval lake sturgeon with yolk sacs, partial yolk sacs, no yolk sacs, or unknown presence/absence of yolk sacs at each sampling night near FIR in the DR in 2012. 


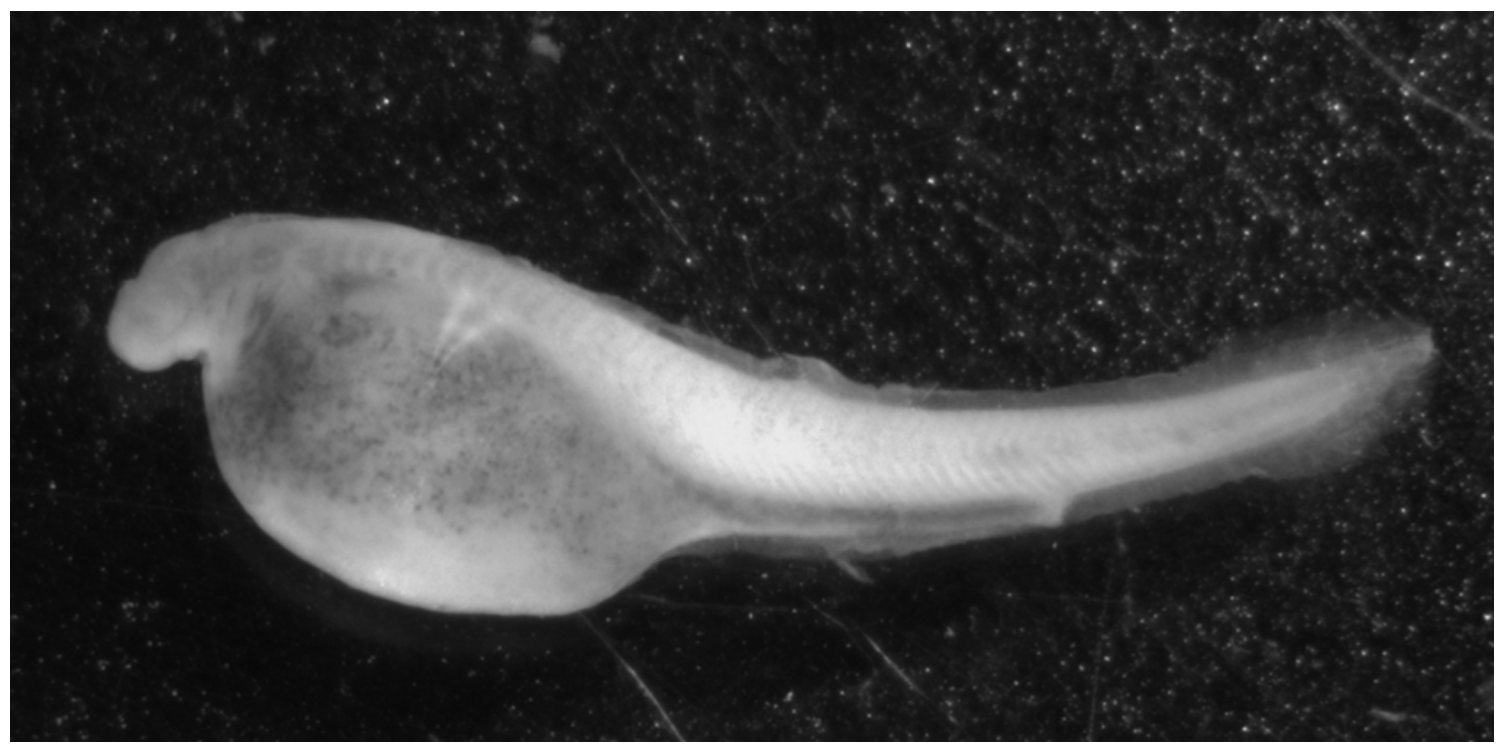

Figure 9: Yolk sac stage larval lake sturgeon (11.29 mm TL) without distinct eye pigment collected from directly downstream of reef bed B at FIR in the DR on 15 May 2012. Image was captured at 60x magnification. 


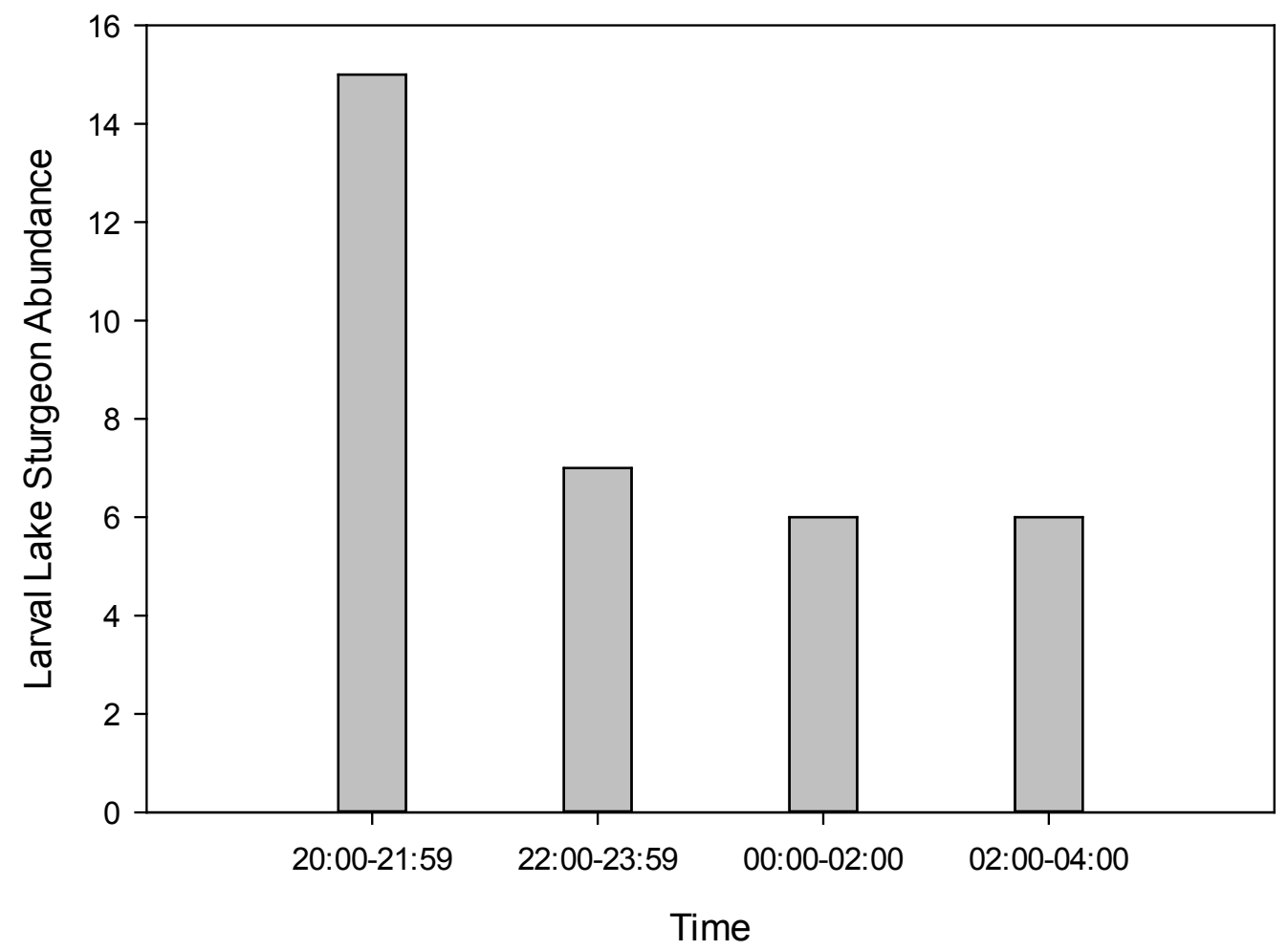

Figure 10: Total number of larval lake sturgeon collected during each time 2 hour set for all sampling nights combined near FIR in the DR in 2012. When a larval lake sturgeon was collected, the midpoint time between net deployment and retrieval times was binned into 4 - 2 hour sampling periods. 


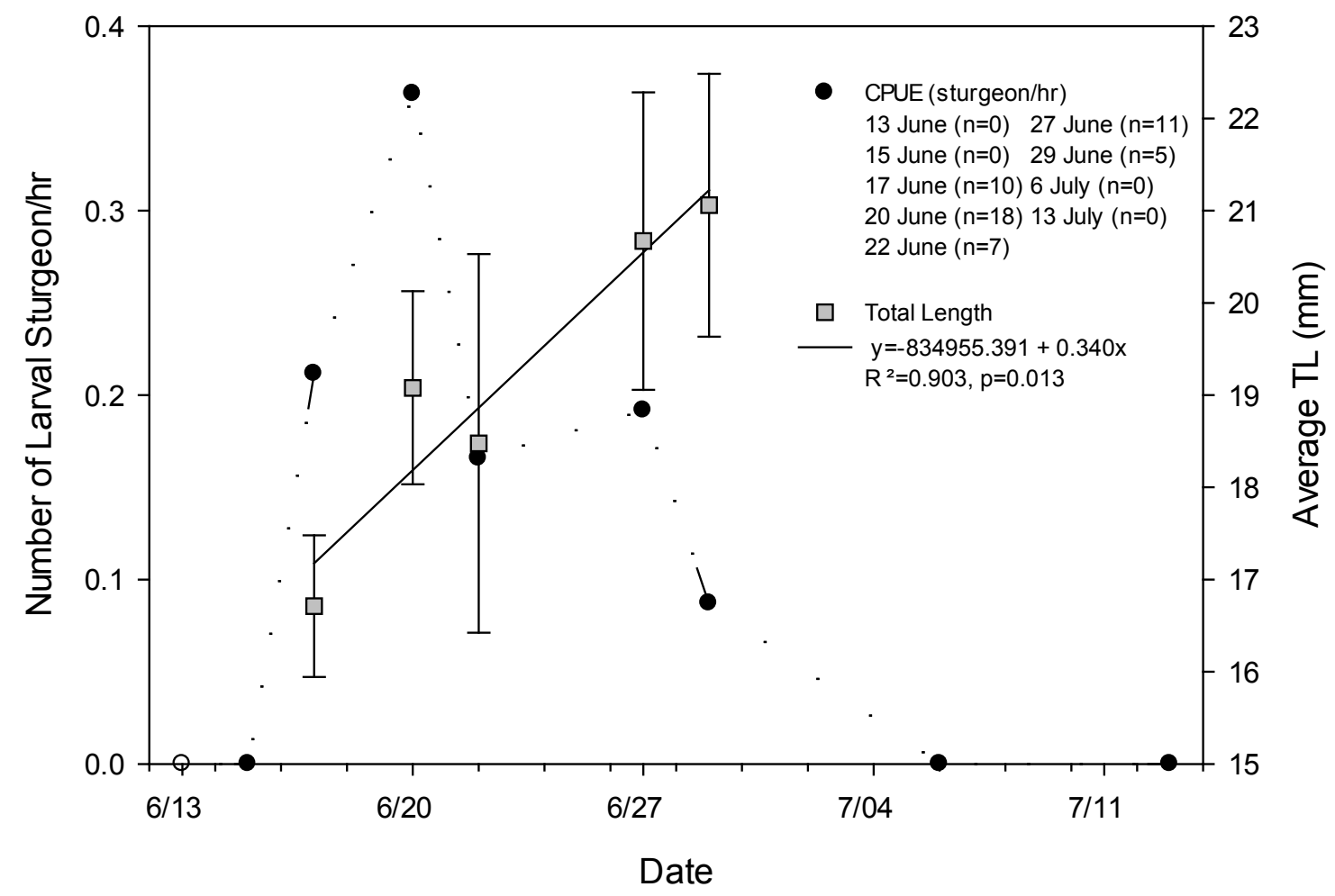

Figure 11: Larval lake sturgeon CPUE (sturgeon/hr) and TL $\pm(\mathrm{SD})$ by sampling date at sites near NCR in the North Channel of the SCR in 2011. 


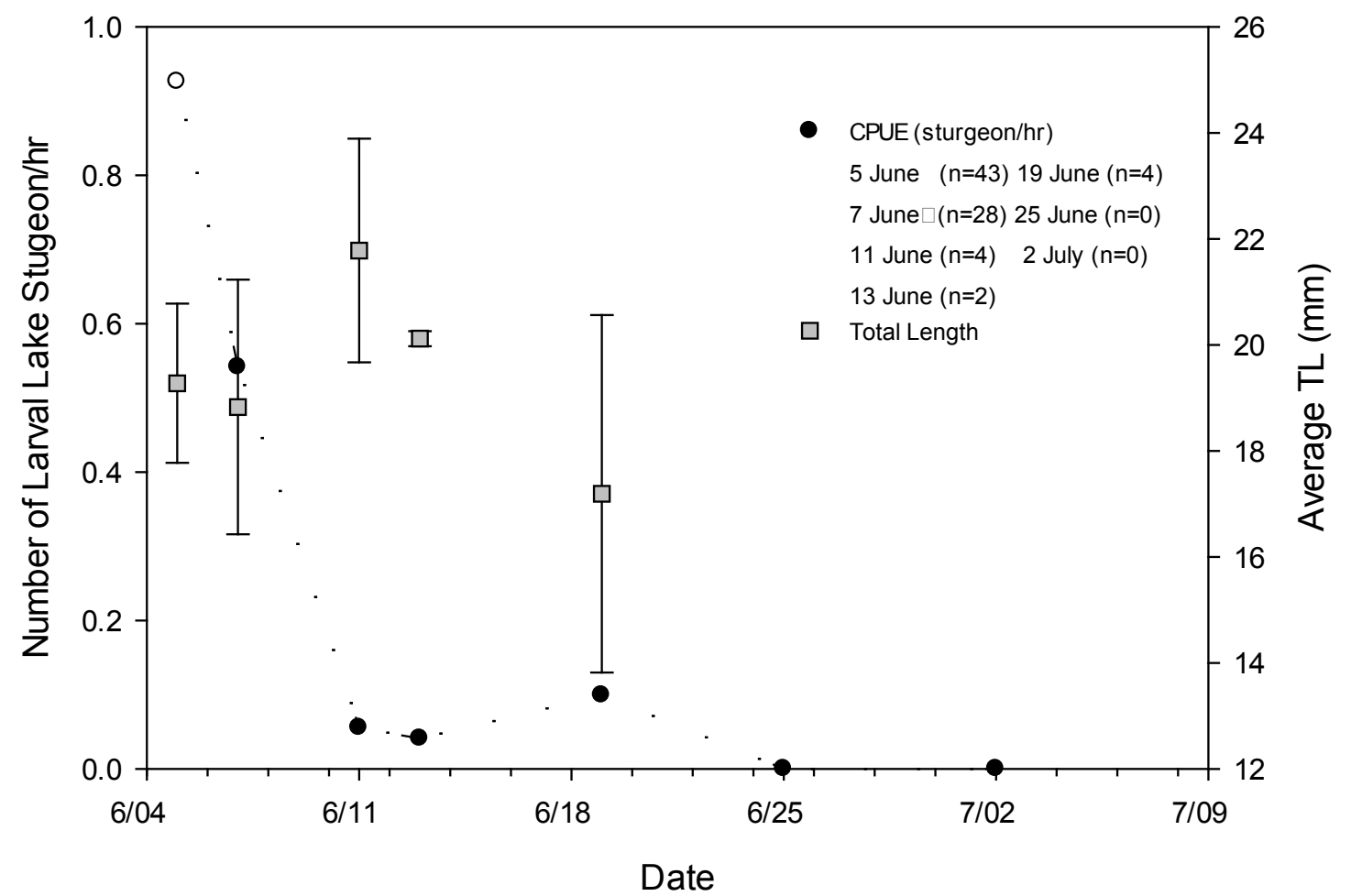

Figure 12: Larval lake sturgeon CPUE (sturgeon/hr) and $T L \pm(\mathrm{SD})$ by sampling date at sites near NCR in the North Channel of the SCR in 2012. On 5 June, for the TL plot, $\mathrm{n}=36$ because 7 individuals were not measured. 


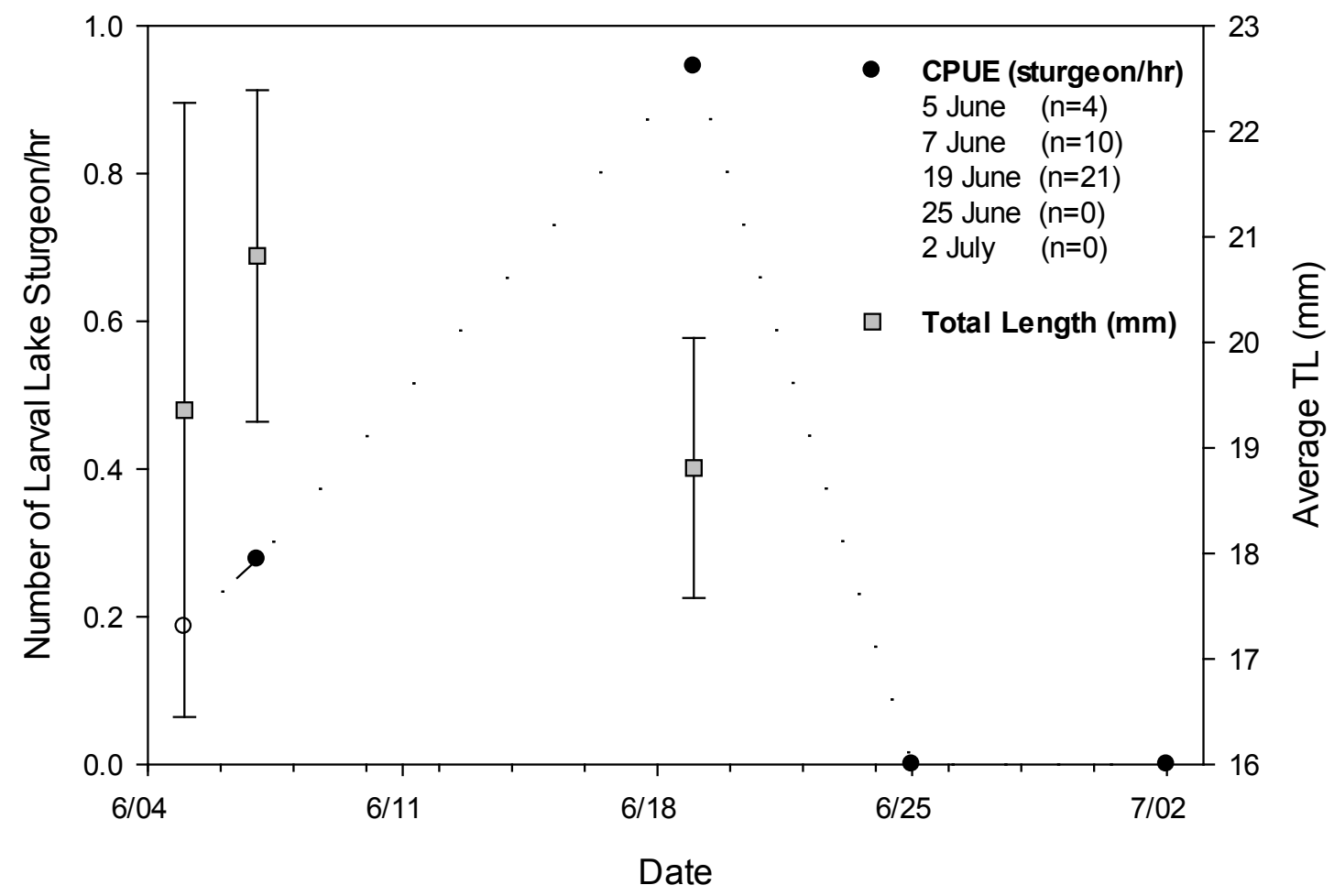

Figure 13: Larval lake sturgeon CPUE (sturgeon/hr) and TL $\pm(\mathrm{SD})$ by sampling date at sites near MCR in the Middle Channel of the SCR in 2012. 


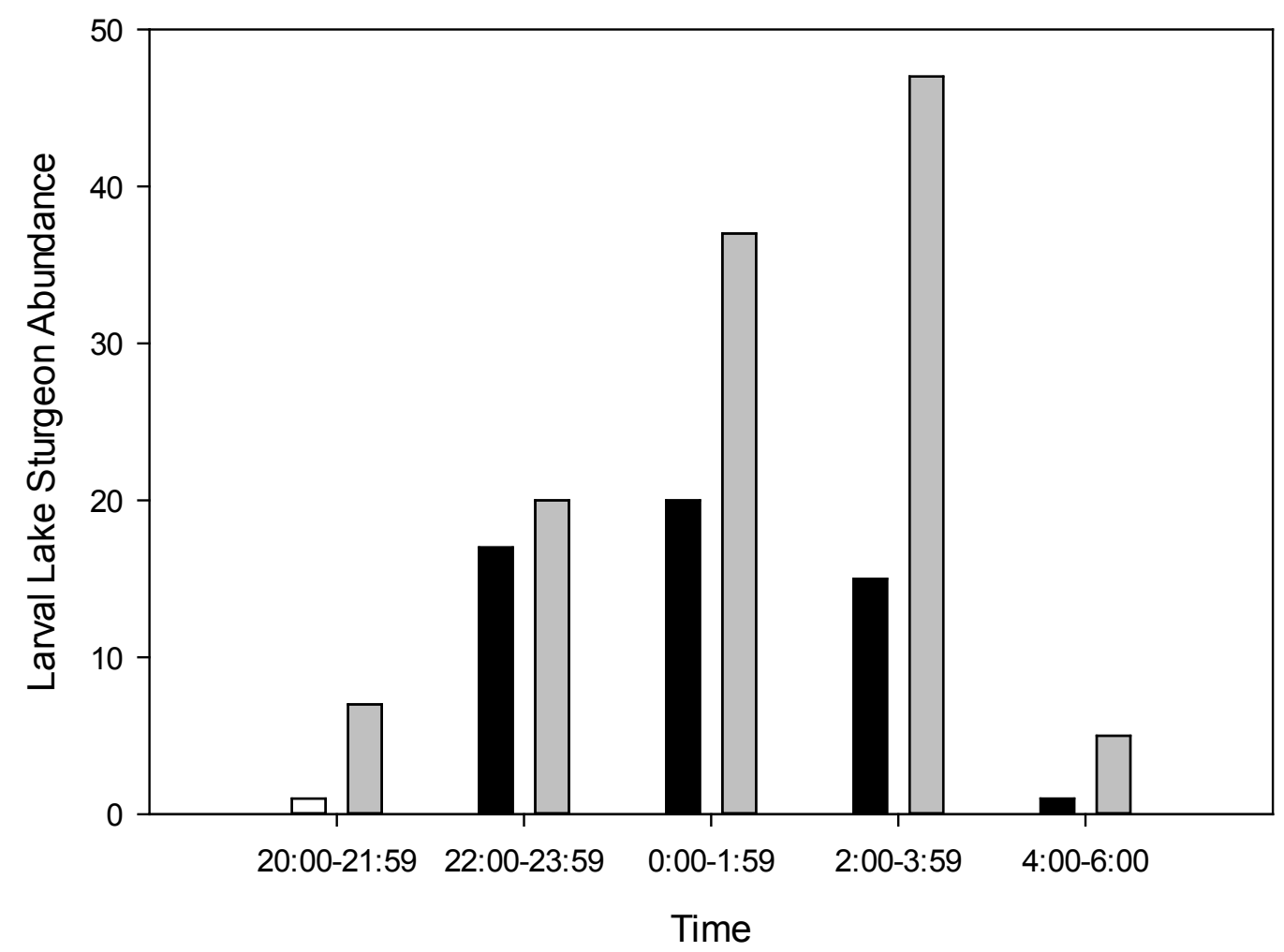

Figure 14: Total number of larval lake sturgeon collected during each net set for all sampling nights combined in the lower SCR in 2011-12. When a larval lake sturgeon was collected, the midpoint time between net deployment and retrieval times was binned into 4 - 2 hour sampling periods. 


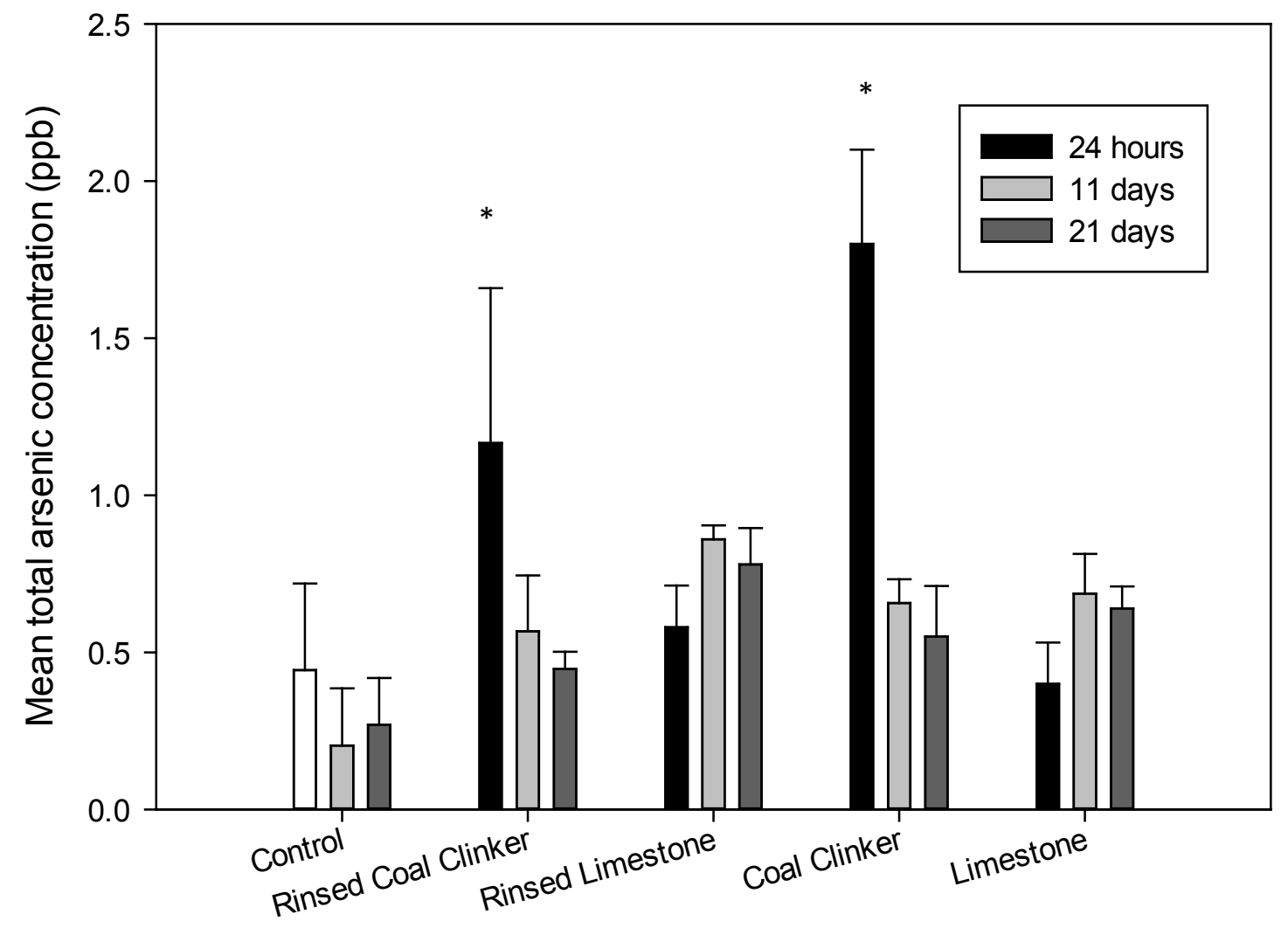

Substrate Treatment

Figure 15: Mean total arsenic concentration (ppb) for each substrate treatment at each sampling time point. Within the coal clinker treatment, mean total arsenic concentration was higher at 24 hours than after 11 days $(\mathrm{p}<0.001)$ and 21 days $(\mathrm{p}<0.001)$. Within the rinsed coal clinker treatment, mean total arsenic concentration was higher at 24 hours than after 11 days $(\mathrm{p}<0.001)$ and 21 days $(\mathrm{p}=0.001)$. 


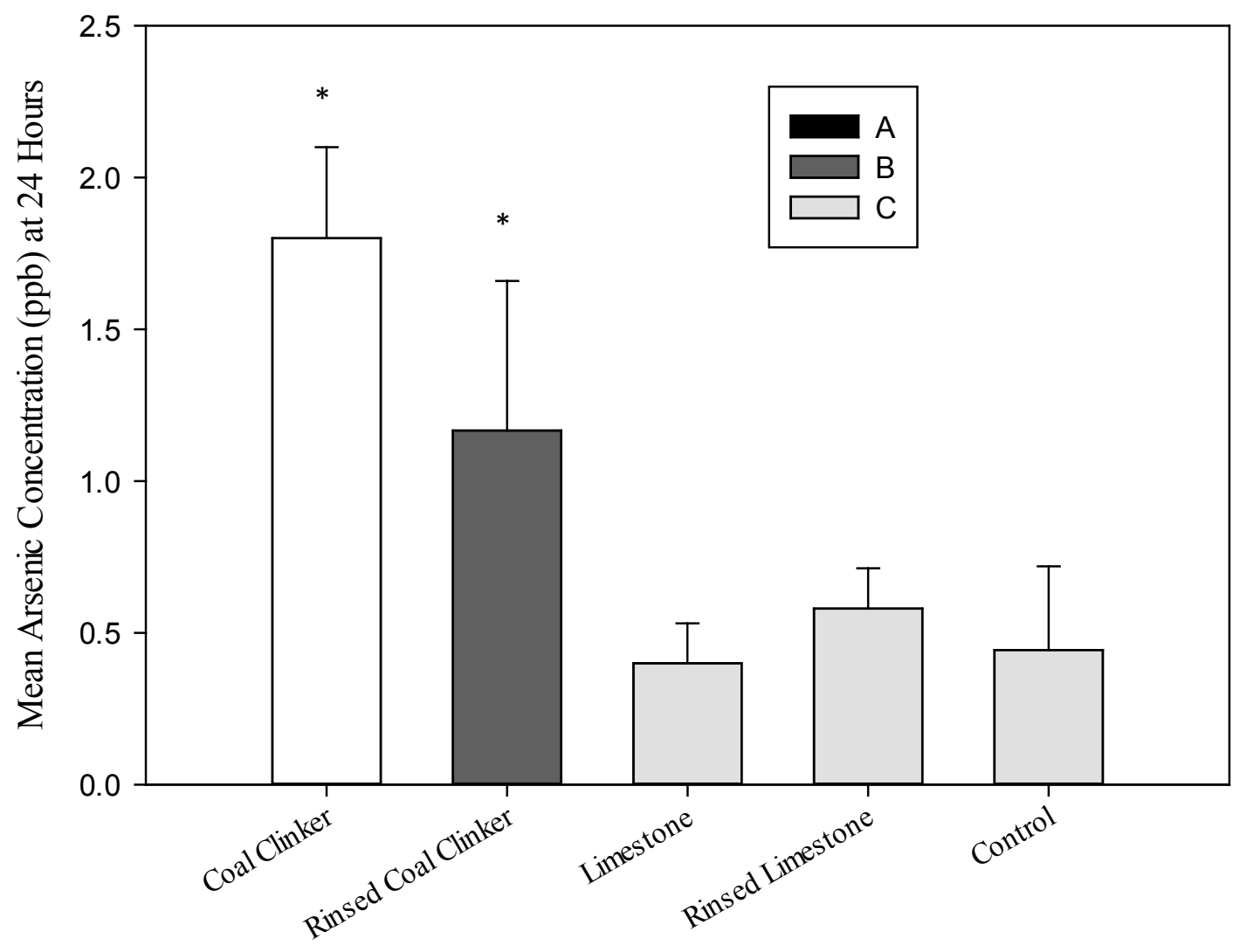

Substrate Treatment

*Statistically significant

Figure 16: Mean arsenic concentration ( $\mathrm{ppb}$ ) for each substrate treatment at the 24 hour sampling point. Mean arsenic concentration was significantly higher in the coal clinker substrate treatment $(A)$, then the rinsed coal clinker treatment $(B)(p=0.006)$, and the substrate treatments in group $C$ (limestone: $p<0.001$, rinsed limestone: $p<0.001$, distilled water: $p<0.001)$. Mean arsenic concentration was also significantly higher in the rinsed coal clinker substrate treatment (B), that the substrate treatments in group $\mathrm{C}$ (limestone: $\mathrm{p}=0.001$ ) rinsed limestone: $\mathrm{p}=0.009$, distilled water $\mathrm{p}=0.002$ ). 


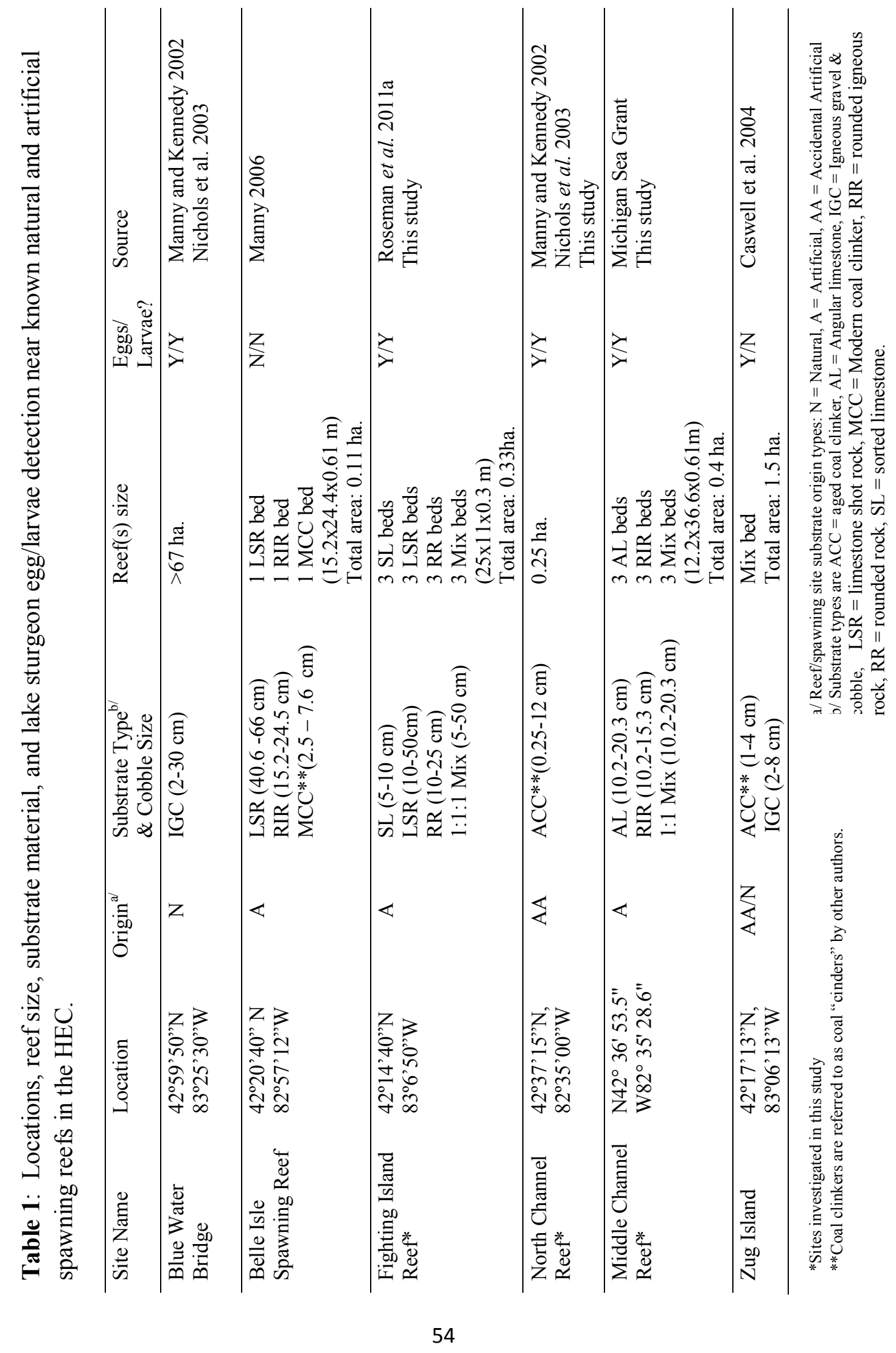




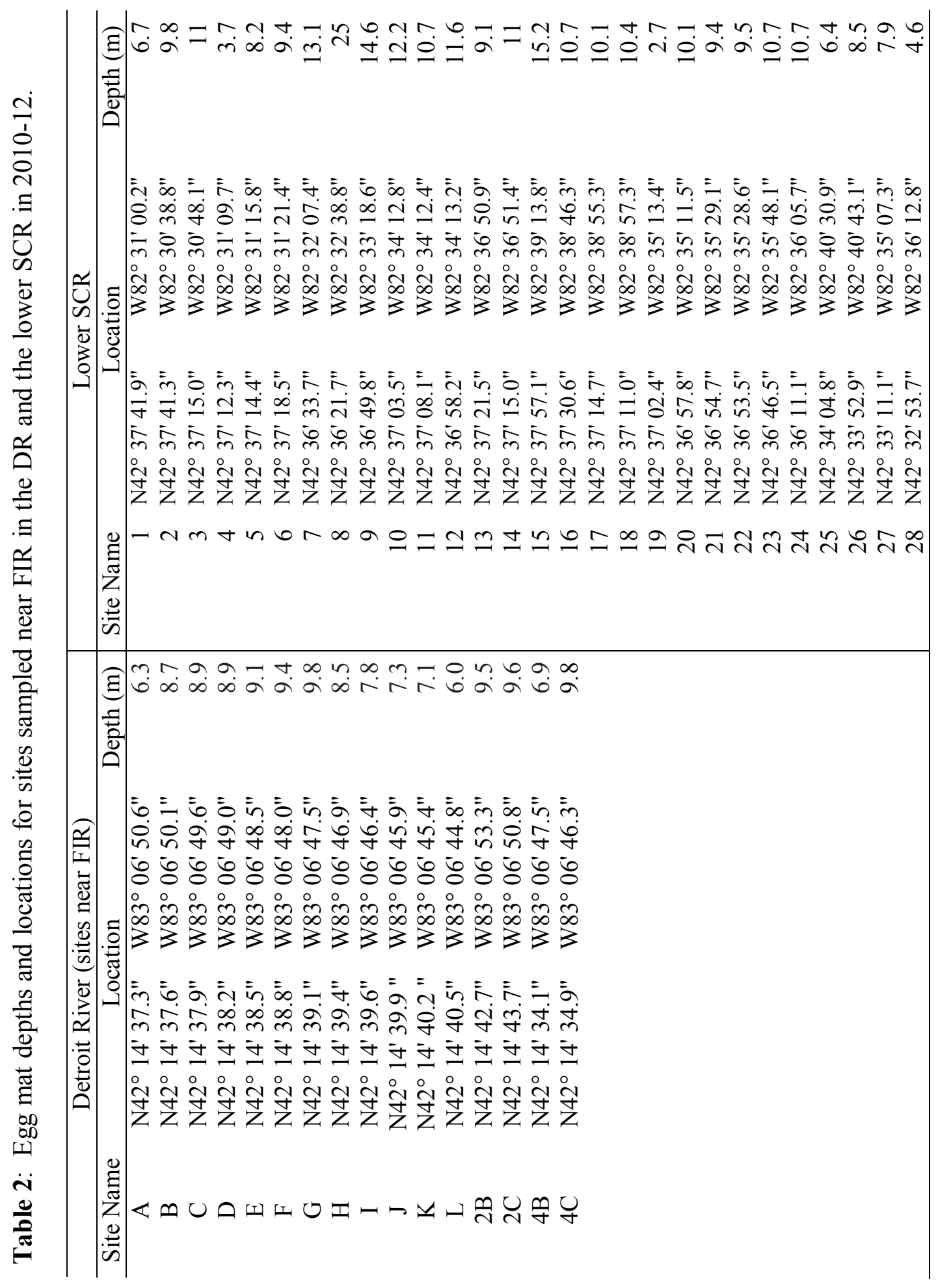


Table 3: Locations of 2011-12 D-Frame and depth-stratified sites in the DR, and 201012 D-Frame and depth-stratified sites in the lower SCR.

\begin{tabular}{|c|c|c|c|c|c|}
\hline \multicolumn{3}{|c|}{ Detroit River (Near FIR) Sites } & \multicolumn{3}{|c|}{ Lower SCR Sites } \\
\hline Site & $\mathrm{N}$ & $\mathrm{W}$ & Site & $\mathrm{N}$ & $\mathrm{W}$ \\
\hline Upstream 1 & 42.24395 & -83.11434 & 1 & 42.62183 & -82.61204 \\
\hline Upstream 2 & 42.24419 & -83.11407 & 2 & 42.62209 & -82.61181 \\
\hline Reef A 1 & 42.24357 & -83.11396 & 3 & 42.62107 & -82.61162 \\
\hline Reef A 2 & 42.2436 & -83.1139 & 4 & 42.62268 & -82.61412 \\
\hline Reef B 1 & 42.24364 & -83.1138 & 5 & 42.62262 & -82.61412 \\
\hline Reef B 2 & 42.24366 & -83.11372 & 6 & 42.62256 & -82.61265 \\
\hline Reef C 1 & 42.24372 & -83.11367 & 7 & 42.62265 & -82.61415 \\
\hline Reef C 2 & 42.24374 & -83.11362 & 8 & 42.62912 & -82.62906 \\
\hline Reef D 1 & 42.2438 & -83.11353 & 9 & 42.62759 & -82.62883 \\
\hline Reef D 2 & 42.24385 & -83.11347 & 10 & 42.63501 & -82.65707 \\
\hline 1 & 42.24395 & -83.1143 & 11 & 42.61563 & -82.58691 \\
\hline 5 & 42.24359 & -83.1139 & 12 & 42.59719 & -82.60574 \\
\hline 2 & 42.24401 & -83.1141 & 13 & 42.61635 & -82.58693 \\
\hline 6 & 42.24366 & -83.1137 & 14 & 42.59789 & -82.60624 \\
\hline 3 & 42.24419 & -83.1141 & 15 & 42.6148 & -82.59150 \\
\hline 7 & 42.24374 & -83.1136 & 16 & 42.61467 & -82.59142 \\
\hline 4 & 42.24419 & -83.1139 & 17 & 42.61539 & -82.58976 \\
\hline 8 & 42.24384 & -83.1135 & 18 & 42.61517 & -82.58962 \\
\hline S-1 & 42.24072 & -83.1111 & 19 & 42.61444 & -82.59320 \\
\hline & & & 20 & 42.61415 & -82.59293 \\
\hline & & & S-1 & 42.62097 & -82.61336 \\
\hline & & & S-2 & 42.62264 & -82.61643 \\
\hline
\end{tabular}


Table 4: Depths, water velocity, total net hours, total larvae, and catch per hour at Dframe sampling sites near FIR in the Detroit River in 2012.

\begin{tabular}{lllllll}
\hline Sites & Description & Depth & $\begin{array}{l}\text { Water } \\
\text { velocity } \\
(\mathrm{m} / \mathrm{s})^{*}\end{array}$ & $\begin{array}{l}\text { Total } \\
\text { larvae }\end{array}$ & $\begin{array}{l}\text { Total net } \\
\text { hours }\end{array}$ & $\begin{array}{l}\text { Catch per } \\
\text { hour }\end{array}$ \\
\hline 1 & Reef A UP & 6.5 & 0.55 & 0 & 50.65 & 0.00 \\
2 & Reef B UP & 8.4 & 0.64 & 1 & 56.08 & 0.02 \\
3 & Reef C UP & 9.7 & 0.56 & 1 & 56.72 & 0.02 \\
4 & Reef D UP & 9.8 & 0.56 & 1 & 54.78 & 0.02 \\
5 & Reef A DN & 6.2 & 0.48 & 1 & 55.5 & 0.02 \\
6 & Reef B DN & 8.3 & 0.70 & 11 & 54.27 & 0.20 \\
7 & Reef C DN & 9.2 & 0.60 & 10 & 56.05 & 0.18 \\
8 & Reef D DN & 9.4 & 0.60 & 9 & 53.73 & 0.17 \\
\hline & & & Totals: & 34 & 437.78 & 0.08 \\
\hline
\end{tabular}

* Water velocity was measured with a Marsh McBirney Flo-Mate ${ }^{\mathrm{TM}}$ Model 2000 flow meter on 8 June, 2012. 


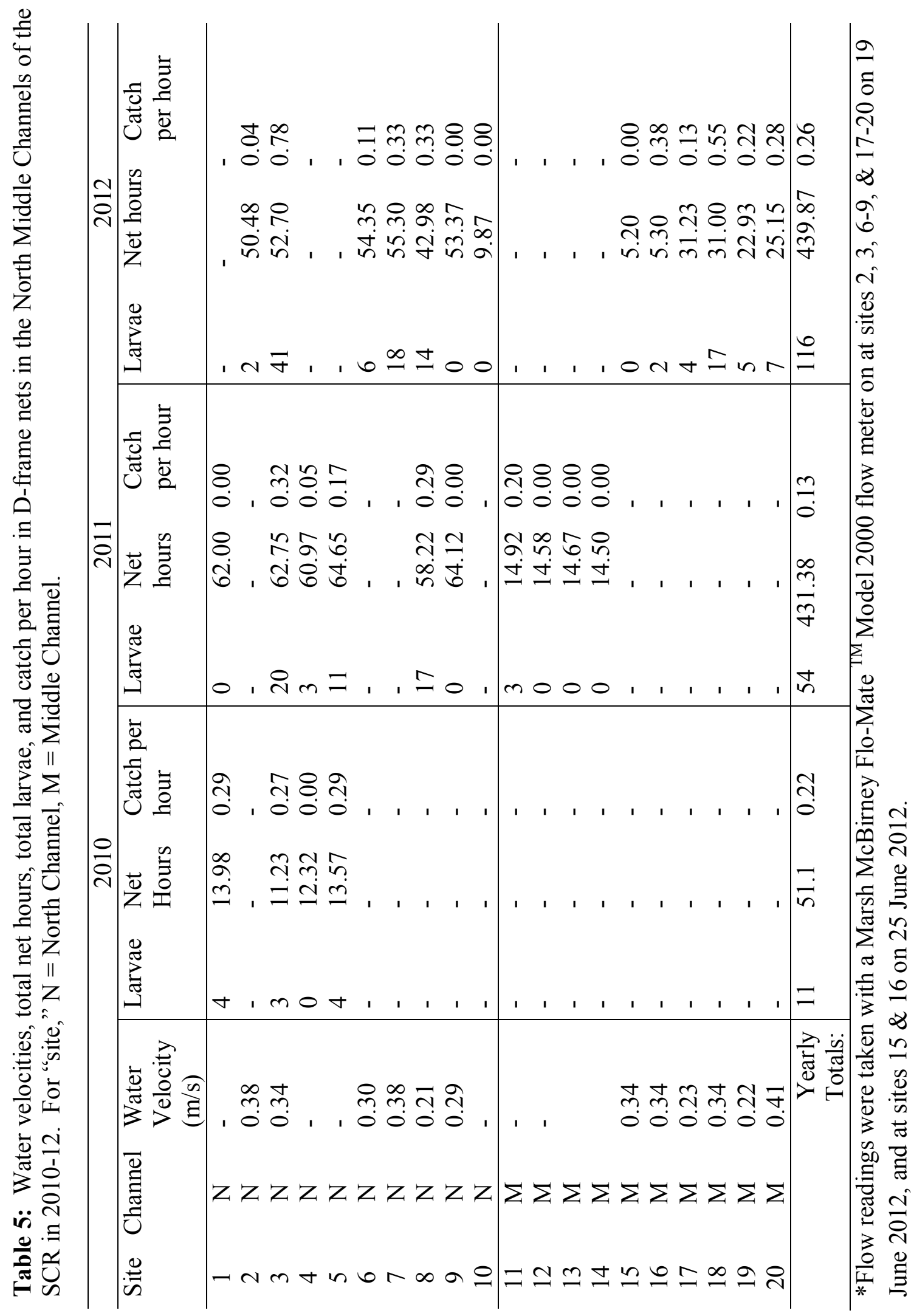


Table 6: Substrate treatment type, number of replicates, size and source.

\begin{tabular}{lcll}
\hline Treatment & Replicates & Size & Source \\
\hline Limestone & 3 & $<15 \mathrm{~cm}$ & Ottawa Lake Quarry, Ottawa Lake, MI \\
Rinsed Limestone & 3 & $<15 \mathrm{~cm}$ & \\
Coal Clinkers & 3 & $<4 \mathrm{~cm}$ & DTE River Rouge Power Plant, Detroit, MI \\
Rinsed Coal Clinkers & 3 & $<4 \mathrm{~cm}$ & $"$ \\
\hline
\end{tabular}


Table 7: Total arsenic concentration ( $\mathrm{ppb}$ ) for all replicated of each substrate treatment 24 hours, 11 days, and 21 days after submerging substrates in distilled water.

\begin{tabular}{lrrr}
\hline & \multicolumn{3}{c}{ Total Arsenic Content (ppb) } \\
\hline Substrate Treatment & 24 Hours & 11 Days & 21 Days \\
\hline Distilled Water 1 & 0.73 & 0.35 & 0.44 \\
Distilled Water 2 & 0.42 & 0 & 0.20 \\
Distilled Water 3 & 0.18 & 0.26 & 0.17 \\
\hline Rinsed Coal Clinkers 1 & 0.60 & 0.41 & 0.51 \\
Rinsed Coal Clinkers 2 & 1.4 & 0.76 & 0.41 \\
Rinsed Coal Clinkers 3 & 1.5 & 0.53 & 0.42 \\
\hline Rinsed Limestone 1 & 0.63 & 0.84 & 0.67 \\
Rinsed Limestone 2 & 0.43 & 0.83 & 0.77 \\
Rinsed Limestone 3 & 0.68 & 0.91 & 0.90 \\
\hline Coal Clinkers 1 & 1.5 & 0.71 & 0.57 \\
Coal Clinkers 2 & 1.8 & 0.69 & 0.38 \\
Coal Clinkers 3 & 2.1 & 0.57 & 0.70 \\
\hline Limestone 1 & 0.26 & 0.55 & 0.56 \\
Limestone 2 & 0.52 & 0.71 & 0.69 \\
Limestone 3 & 0.42 & 0.80 & 0.67 \\
\hline
\end{tabular}


Table 8: ANOVA table for 2 way repeated measures analysis.

\begin{tabular}{lrllll}
\hline Source of Variation & DF & SS & MS & F & P \\
\hline Jar Replicate & 2 & 0.0732 & 0.0366 & & \\
Substrate Treatment & 4 & 2.342 & 0.585 & 9.394 & $0.004^{*}$ \\
Substrate Treatment x Jar Replicate & 8 & 0.499 & 0.0623 & & \\
Time Sampled & 2 & 0.998 & 0.499 & 21.324 & $0.007^{*}$ \\
Time Sampled x Jar Replicate & 4 & 0.0936 & 0.0234 & & \\
Substrate Treatment x Time Sampled & 8 & 3.135 & 0.392 & 11.665 & $<0.001^{*}$ \\
Residual & 16 & 0.537 & 0.0336 & & \\
\hline Total & 44 & 7.678 & 0.174 & & \\
\hline
\end{tabular}

*Statistically significant 


\subsection{REFERENCES}

Auer, N. A., 1996: Importance of habitat and migration to sturgeons with emphasis on lake sturgeon. Can. J. Fish. Aquat. Sci. 53(Suppl. 1), 152-160.

Auer, N. A.; Baker, E. A., 2002: Duration and drift of larval lake sturgeon in the Sturgeon River, Michigan. J. Appl. Ichthyol. 18, 557-564.

Baker, J. P., 1980: The distribution, ecology, and management of the lake sturgeon (Acipenser fulvescens Rafinesque) in Michigan. Fisheries Research Report No. 1883. Michigan Department of Natural Resources, Ann Arbor, MI.

Boase, J.; Kennedy, G. W, 2008: Fighting Island Pre-Construction Progress Report (Fall 2006 - Spring 2008) U.S. Fish Wildl. Serv., Alpena Fish Research Office. Alpena, Michigan.

Baldwin, N. A.; Saalfeld, R. W.; Dochoda, M. R.; Buettner, H. J.; Eshenroder, R. L., 2009: Commercial Fish Production in the Great Lakes 1867-2006 [online]. Available from http://www.glfc.org/databases/commercial/commerc.php.

Deng, X.; Van Eenennaam, J. P; Doroshov, S. I., 2002: Comparison of early life stages and growth of green and white sturgeon. American Fisheries Society. 28, 237-248.

Caswell, N. M.; Peterson, D. L.; Manny, B. A.; Kennedy, G. W., 2004: Spawning by lake sturgeon (Acipenser fulvescens) in the Detroit River. J. Appl. Ichthyol. 20, 1-6.

D'Amours, J.; Thibodeau, S.; Fortin, R., 2001: Comparison of lake sturgeon (Acipenser fulvescens), Stizostedion spp, Catostomus spp., Moxostoma spp., quillback (Carpiodes cyprinus), and mooneye (Hiodon tergisius) larval drift in Des Prairies River, Québec. Can. J. Zool. 79, 1472-1489.

Daugherty, D. J.; Sutton, T. M.; Elliot, R. F., 2008: Suitability modeling of lake sturgeon habitat in five northern Lake Michigan tributaries: implications of population rehabilitation. Restor. Ecol. 17, 245-257.

Dumont, P.; D'Amours, J.; Thibodeau, S.; Dubuc, N.; Verdon, R.; Garceau, P.; Mailhot, Y.; Fortin, R., 2011: Effects of the development of a newly created spawning ground in the Des Prairies River (Quebec, Canada) on the reproductive success of lake sturgeon (Acipenser fulvescens). J. Appl. Ichthy.27, 394-404.

Goodyear, C. S.; Edsall, T. A.; Ormsby Dempsey, D. M.; Moss, G. D.; and Polanski, P. E., 1982a: Atlas of the spawning and nursery areas of Great Lakes fishes: St. Clair River, Vol 6.U.S. Fish and Wildlife Service, Washington, DC FWS/OBS$82 / 52$. 
Goodyear, C. S.; Edsall, T. A.; Ormsby Dempsey, D. M.; Moss, G. D.; and Polanski, P. E., 1982a. Atlas of the spawning and nursery areas of Great Lakes fishes: Detroit River, Vol 8.U.S. Fish and Wildlife Service, Washington, DC FWS/OBS$82 / 52$.

Harkness, W. J. K.; Dymond, J. R., 1961: The Lake Sturgeon. Ontario Department of Lands and Forests, Fish and Wildlife Branch, Ontario.

Hay-Chmielewski, E. M.; Whelan, G. E., 1997: Lake sturgeon rehabilitation strategy. Fisheries Division Michigan Deptartment of Natural Resources Special Report No. 18. Ann Arbor, MI.

Johnson, J. H.; LaPan, S. R.; Klindt, R. M.; Schiavone, A., 2006: Lake sturgeon spawning on artificial habitat in the St Lawrence River. J. Appl. Ichthyol. 22, 465470.

Kempinger, J. J., 1988: Spawning and early life history of lake sturgeon in the Lake Winnebago system, Wisconsin. Am. Fish. Soc. Symp. 5, 110-122.

Kerr, S. J.; Davidson, M. J.; Funnel, E., 2010: A review of lake sturgeon habitat requirements and strategies to protect and enhance sturgeon habitat. Fisheries Policy Section, Biodiversity Branch. Ontario Ministry of Natural Resources, Peterborough, ON.58 pp + appendices.

Khoroshko, P.N.; Vlasenko, A.D. 1970: Artificial spawning grounds of sturgeon. J. Ichthyol. 10, 286-292.

Larson, J., 1981: A history of the Detroit District U.S. army corps of engineers. U.S. Army Corps of Engineers, Detroit, MI. 215 pp.

LaHaye, M.; Branchaud, A.; Gendron, M.; Verdon, R.;\& Fortin, R., 1992: Reproduction, early life history, and characteristics of the spawning grounds of the lake sturgeon (Acipenser fulvescens) in Des Prairies and L'Assomption rivers, near Montreal, Quebec. Canadian Journal of Zoology, 70, 1681-168.

Manny, B. A.; Kennedy, G.W., 2002: Known lake sturgeon (Acipenser fulvescens) spawning habitat in the channel between lakes Huron and Erie in the Laurentian Great Lakes. J. Appl. Ichthyol. 18, 486-490. 
Nichols, S.; Kennedy, G.; Crawford, E.; Allen, J.; French, J.; Black, G.; Blouin, M.; Hickey, J.; Chernyák, S.; Haas, R.; Thomas, M., 2003. Assessment of lake sturgeon (Acipenser fulvescens) spawning efforts in the lower St. Clair River, Michigan. J.. Great Lakes Res. 29, 383-391.

Nikolsky, G.V. 1963. The ecology of fishes. Academic Press, London, 352pp.

Post, H., 1890: The sturgeon: some experiments in hatching. Trans. Am. Fish. Soc. 19, $36-40$

Read, J.; Manny, B. A., 2006: Monitoring element of the Belle Isle/Detroit River Sturgeon Habitat Restoration, Monitoring, and Education Project. Research completion report to Michigan Sea Grant Program, Univ. of Michigan, 401 E. Liberty, Suite 330, Ann Arbor, MI. 85pp.

Rochard, E.; Castelnaud, G.; Lepage, M., 1990: Sturgeons (Pisces: Acipenseridae); threats and prospects. Journal of Fish Biology. 37 (Suppl. A), 123-132.

Roseman, E. F.; Manny, B. A.; Boase, J.; Child, M.; Kennedy, G. W.; Craig, J.; Soper, K.; Drouin, R., 2011a: Lake sturgeon response to a spawning reef constructed in the Detroit River. J. of Appl. Ichthyol. 27, 66-76.

Roseman, E.F.; Boase, J.; Kennedy, G.W.; Craig, J., 2011b. Adaptation of two techniques for sampling fish eggs and larvae in deep rivers. J. of Appl. Ichthyol. 27(Suppl. 2), 89-92.

Smith, K. M.; King, D. K., 2005: Dynamics and extent of larval lake sturgeon Acipenser fulvescens drift in the Upper Black River, Michigan. J. Appl. Ichthyol. 21, 161-168.

Smith, S., 1968: Species succession and fishery exploitation in the Great Lakes. J. Fish. Res. Bd. of Canada. 25, (667-693).

Wang, J. C. S. 2006: Early life history comparison of the green sturgeon, Acipenser medirostris, and white sturgeon, Acipenser transmontanus, of the Sacramento-San Joaquin River Delta, California. U.S. Department of the Interior Bureau of Reclamation Tracy Fish Collection Facility. Byron, California. Technical Bulletin 2006-1. 24 pp.

Wells, L.; McLain, A, 1973: Lake Michigan: man's effects on native fish stocks and other biota.Great Lakes Fishery Commission. Tech. Rep. No. 20. 57 pp. 


\subsection{REFERENCES}

Ahmed, M. F.; Ali, M. A.; Adeel, Z., (eds.) 2001: Technologies for arsenic removal from drinking water. Bangladesh University of Engineering and Technology \& The United Nations University, Bangladesh, India. 19 pp.

Baker, J. P., 1980: The distribution, ecology, and management of the lake sturgeon (Acipenser fulvescens Rafinesque) in Michigan. Fisheries Research Report No. 1883. Michigan Department of Natural Resources, Ann Arbor, MI, 95 pp.

Benson, C. H.; Bradshaw, S., 2011: User guidelines for coal bottom ash and boiler slag in green infrastructure construction. Recycled Materials Resource Center, University of Madison-Wisconsin, Madison, WI.

EPA, 1996: 1995 Updates: Water QualityCriteria Documents of Aquatic Life in Ambient Water. U.S. Environ. Protection Agency Rep. 820-B-96-001.

Caswell, N. M.; Peterson, D. L.; Manny, B. A.; Kennedy, G. W., 2004: Spawning by lake sturgeon (Acipenser fulvescens) in the Detroit River. J. Appl. Ichthyol. 20, 1-6.

Goodarzi, F. 2009: Enivronmental assesment of bottom ash from coal-fired power plants. The Open Enivronmental \& Biological Monitoring Journal. 2, 1-10.

Han, B.; Runnells, T.; Zimbron, J.; Wickramasinghe, R., 2002: Arsenic removal from drinking water by flocculation and microfiltration. Desalination. 145, 293-298.

Irwin, R.J., 1997: Environmental Contaminants Encyclopedia Arsenic Entry. National Park Service, Water Resources Divisions, Water Operations Branch, Fort Collin, $\mathrm{CO}, 114 \mathrm{pp}$.

Manny, B. A.; Kennedy, G.W., 2002: Known lake sturgeon (Acipenser fulvescens) spawning habitat in the channel between lakes Huron and Erie in the Laurentian Great Lakes. J. Appl. Ichthyol. 18, 486-490.

Read, J.; Manny, B. A., 2006: Monitoring element of the Belle Isle/Detroit River Sturgeon Habitat Restoration, Monitoring, and Education Project. Research completion report to Michigan Sea Grant Program, Univ. of Michigan, 401 E. Liberty, Suite 330, Ann Arbor, MI. 85 pp. 
Nichols, S.; Kennedy, G.; Crawford, E.; Allen, J.; French, J.; Black, G.; Blouin, M.; Hickey, J.; Chernyák, S.; Haas, R.; Thomas, M., 2003. Assessment of lake sturgeon (Acipenser fulvescens) spawning efforts in the lower St. Clair River, Michigan. J. Great Lakes Res. 29, 383-391.

Sorenson, E. M. 1991. Metal Poisoning in Fish. CRC Press Inc.Boca Raton, FL. 374 pp. 


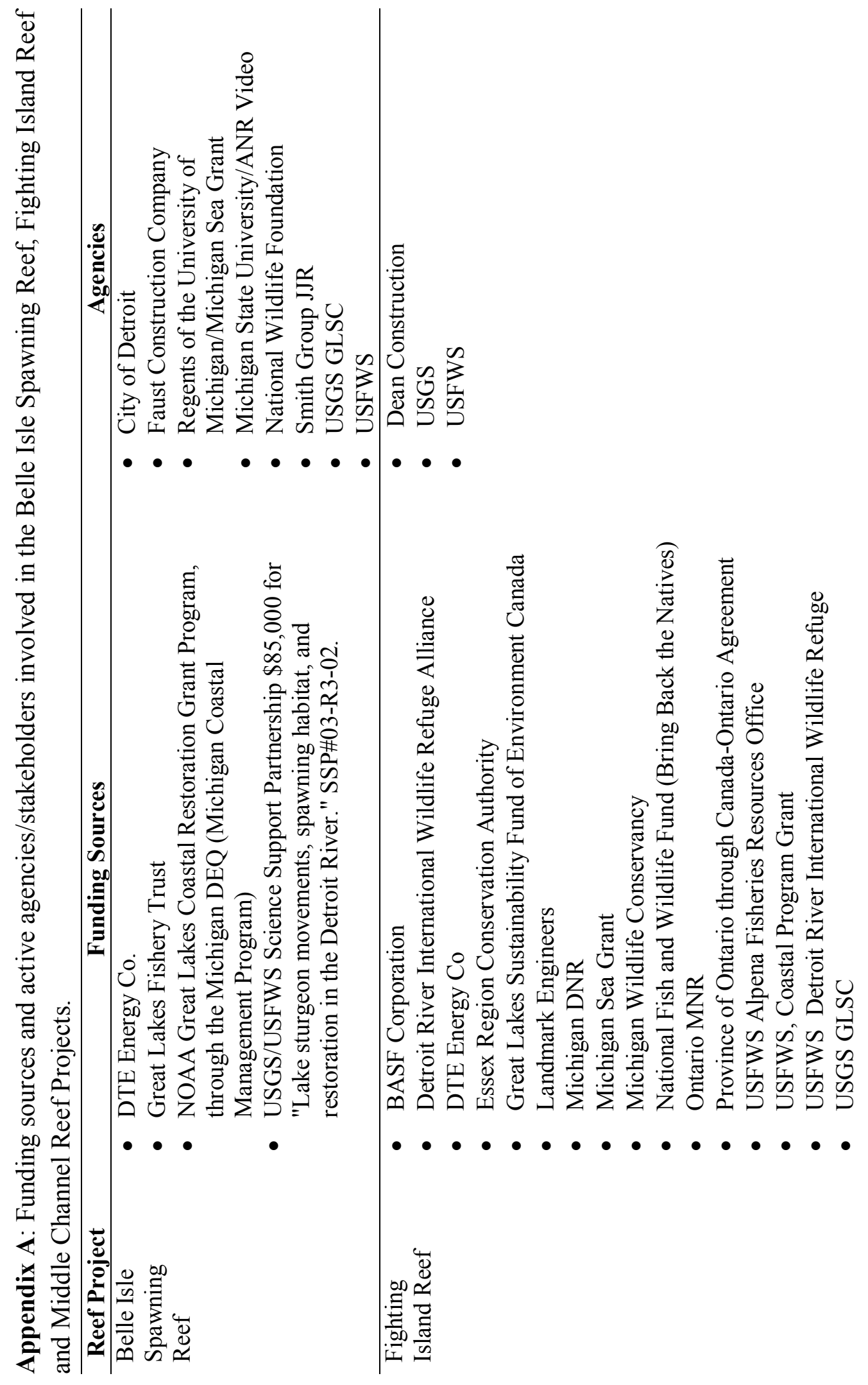




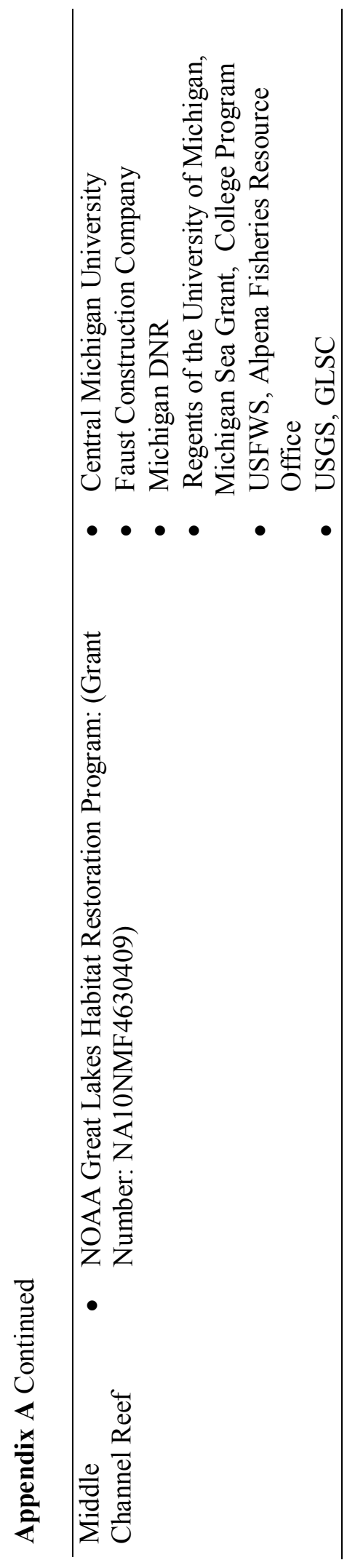




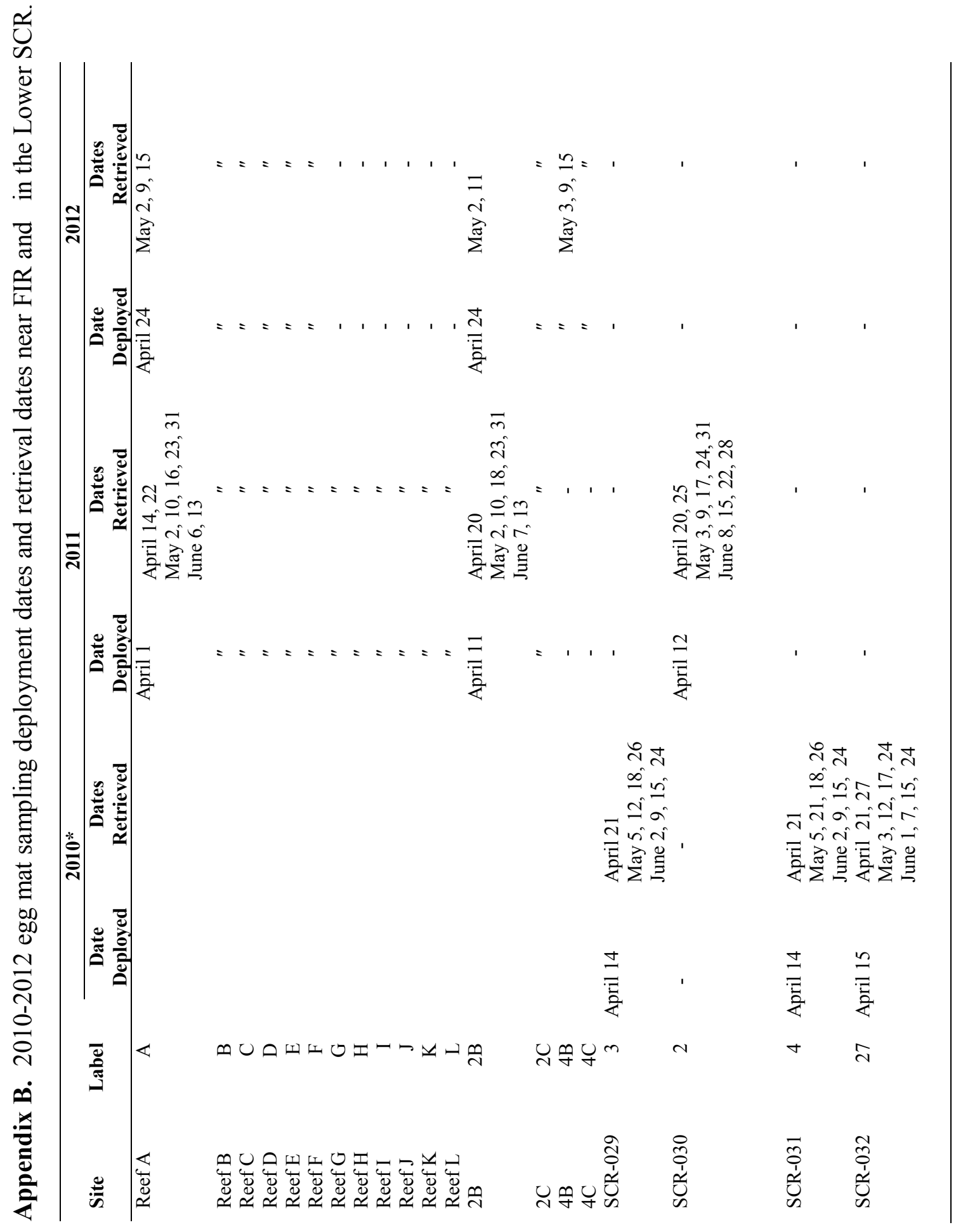




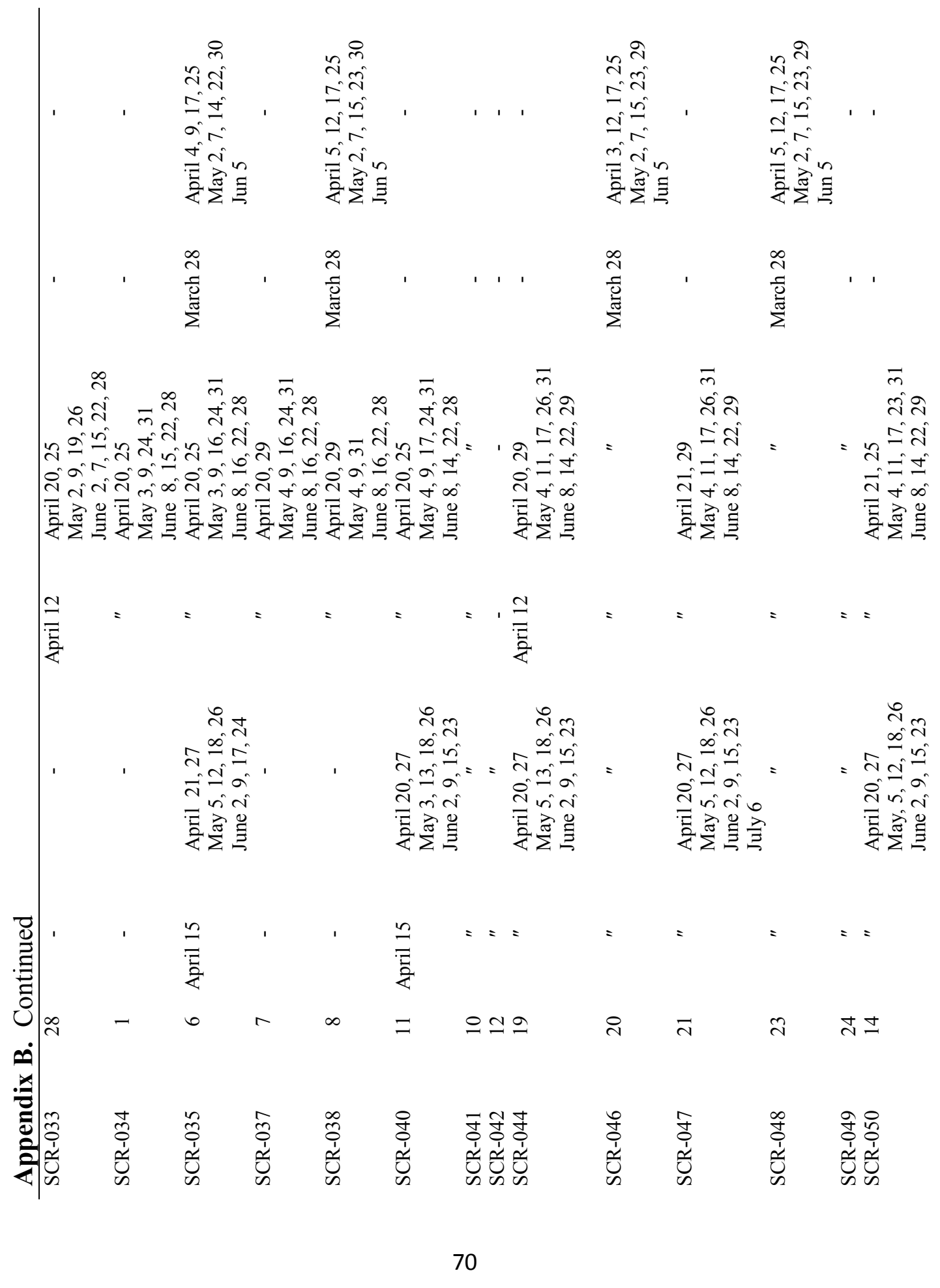




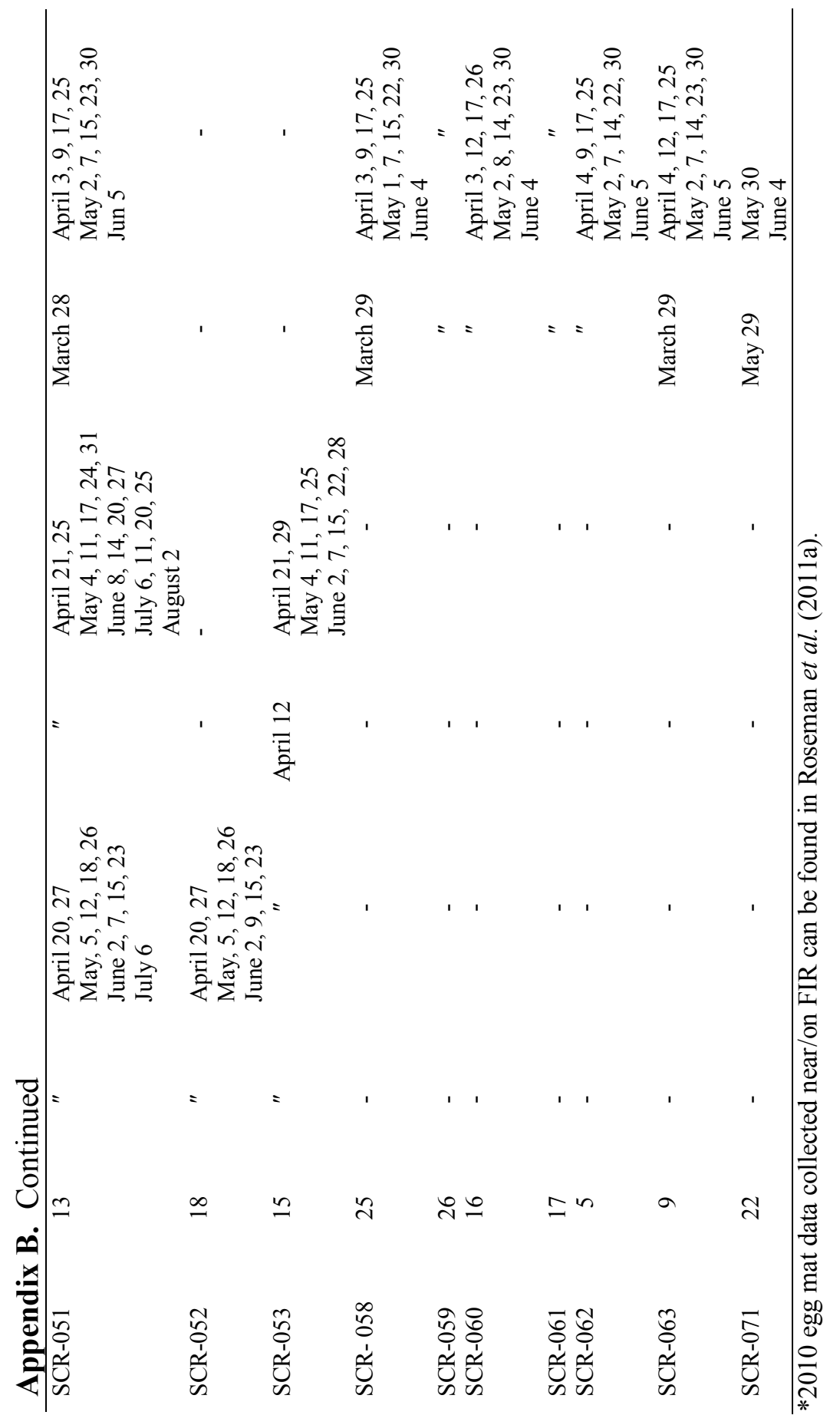

